Misallocation and Capital Market Integration: Evidence from India

$$
\text { by }
$$

Natalie Bau, UCLA and CEPR Adrien Matray, Princeton University

Griswold Center for Economic Policy Studies

Working Paper No. 263, January 2020 


\title{
Misallocation and Capital Market InTEGRATION: EvidenCE From INDIA*
}

\author{
Natalie $\mathrm{Bau}^{\dagger} \quad$ Adrien Matray
}

\begin{abstract}
We show that foreign capital liberalization reduces capital misallocation and increases aggregate productivity using a natural experiment. The staggered liberalization of access to foreign capital across disaggregated Indian industries allows us to identify changes in firms' input wedges, overcoming major challenges in the measurement of the effects of changing misallocation. For domestic firms with initially high marginal revenue products of capital (MRPK)/high sales to capital ratios, liberalization increased revenues by $18 \%$, physical capital by $60 \%$, wage bills by $26 \%$, and reduced the marginal revenue product of capital by $43 \%$ relative to low MRPK firms. There were no effects on firms with low MRPK. The effects of liberalization are largest in areas with less developed local banking sectors, indicating that foreign investors may substitute for an efficient banking sector. Finally, we develop a method to use natural experiments to estimate the lower bound effect of changes in misallocation on manufacturing productivity. We find that this liberalization episode increased the aggregate productivity of the Indian manufacturing sector by at least $6.5 \%$.
\end{abstract}

\footnotetext{
*We thank David Baqaee, Dave Donaldson, Emmanuel Farhi, Pete Klenow, Diego Restuccia, Richard Rogerson, Martin Rotemberg, Chad Syverson, Christopher Udry, Liliana Varela, conference participants at the Stanford King Center Conference on Firms, Trade, and Development, CEPR Macroeconomics and Growth Meetings, CIFAR IOG meetings, and EPED, and seminar participants at the Toulouse School of Economics, INSEAD, CREST, University of Paris-Dauphine, Georgetown, the World Bank, Dartmouth, UToronto, UCLA, and Guelph for helpful comments and discussions. Carl Kontz, Palermo Penano, Brian Pustilnik, and Mengbo Zhang provided exceptional research assistance. We are also grateful to the International Growth Centre, the Julis-Rabinowitz Center for Public Policies, and the Griswold Center of Economic Policy Studies (Princeton), which funded this project.

${ }^{\dagger}$ UCLA and CEPR. (email: nbau@ucla.edu)

${ }_{\ddagger}^{\ddagger}$ Princeton. (email: amatray@princeton.edu)
} 


\section{Introduction}

The misallocation of resources across firms may have a meaningful effect on aggregate productivity, particularly in low-income countries (e.g. Restuccia and Rogerson, 2008; Hsieh and Klenow, 2009; Bento and Restuccia, 2017). Yet, despite the potential importance of misallocation for explaining economic disparities, quantifying its aggregate effects and identifying the best policy tools to reduce it are complicated by two challenges.

First, on the measurement side, it is common to attribute all - or much of - the crosssectional dispersion in the observed marginal returns to firms' inputs to misallocation. This creates upward bias in measures of misallocation due to measurement error (Bils, Klenow, and Ruane, 2018; Rotemberg and White, 2017; Gollin and Udry, 2019), model misspecification (Haltiwanger, Kulick, and Syverson, 2018; Nishida, Petrin, Rotemberg, and White, 2017), volatility of productivity paired with the costly adjustment of inputs (Asker, Collard-Wexler, and De Loecker, 2014; Gollin and Udry, 2019), unobserved heterogeneity in technology (Gollin and Udry, 2019), and informational frictions and uncertainty (David, Hopenhayn, and Venkateswaran, 2016; David and Venkateswaran, 2019). These measurement challenges are in turn likely to inflate estimates of the aggregate gains from reducing misallocation.

Second, on the policy side, even if one were able to fully correct for mismeasurement and quantify the effect of changes in misallocation on aggregate productivity, the specific sources of misallocation are difficult to identify from aggregate comparisons. ${ }^{1}$ This leaves policymakers with limited information about what levers to pull to reduce misallocation (Syverson, 2011). Yet, in low-income countries, where there are likely to be large firmlevel frictions in the allocation of resources, policies that reduce misallocation could prove to be a powerful tool to foster economic growth.

An unusual natural experiment in India allows us to make progress on both the measurement front and the policy front. Over the 2000s, India introduced the automatic approval of foreign direct investments up to $51 \%$ of domestic firms' equity, potentially reducing capital market frictions. Using the staggered introduction of the policy across industries, we implement a difference-in-differences framework to estimate the effects of foreign capital liberalization on the misallocation of capital across firms. This setting allows us to isolate changes in the observed marginal revenue product of capital due to the policy from changes due to measurement error or other shocks.

We find that the liberalization reduced capital misallocation by increasing capital for

1. To quantify the overall degree of misallocation, the literature usually compares outcomes such as the distribution of marginal revenue products across units of production after controlling for different characteristics and attributes the residual dispersion to misallocation. Since this method of quantifying misallocation typically does not show which characteristics causally affect the residual dispersion in marginal products, it is mostly silent on what policies would be required to reduce misallocation in lowincome countries. An important exception is David and Venkateswaran (2019), which makes progress on distinguishing various sources of dispersion. 
firms with the highest marginal returns to capital prior to the reform. Put simply, we document the fact that firms with relatively high sales to capital ratios greatly expanded their capital due to the liberalization. We develop a method, based on the theoretical results of Petrin and Levinsohn (2012) and Baqaee and Farhi (2019), to translate our quasi-experimental microeconomic estimates into a lower bound measure of the effect of the policy on aggregate manufacturing productivity. Our proposed method uses exogeneous variation to generate estimates of the effect of changing misallocation on a measure of aggregate productivity under relatively weak identifying assumptions and importantly, without relying on cross-sectional dispersion in marginal revenue products.

To measure the effects of the reform, we hand-collected data on industry-level liberalization episodes in 2001 and 2006. Combining this policy variation with a panel of large and medium-sized Indian firms, we investigate whether the reform reduced misallocation by testing whether the policy had differential effects depending on firms' ex ante marginal revenue products of capital (henceforth "MRPK"). By exploiting within-industry variation in firms' MRPK, this empirical strategy requires milder identification assumptions for determining whether misallocation decreased than standard difference-in-differences estimators, as it allows us to control for the average effect of belonging to a deregulated industry. Thus, determining whether the policy reduced misallocation only requires that industry-level shocks, which may be correlated with the policy change, affect high and low MRPK firms in the same industry in the same way. In our most stringent specifications, we can account for any unobserved shocks or differences in time trends at the disaggregated industry, state, and size decile level.

We find that high MRPK firms in deregulated industries increase their physical capital by $60 \%$, revenues by $18 \%$, wage bills by $26 \%$, and reduce their MRPK by $43 \%$ relative to low MRPK firms in response to the policy. In contrast, low MRPK firms are not affected. Since high MRPK firms initially have $140 \%$ higher MRPK, the micro-estimates imply that the policy reduces misallocation. Event study graphs confirm that these effects are not driven by differential pre-trends between high and low MPRK firms within treated industries relative to un-treated industries and provide visual evidence that the reduction in misallocation is not due to mean reversion.

Exploiting geographic variation in local access to credit prior to the reform, we also find that the effects of liberalization on misallocation are largest in areas where the local banking sector was less developed. This is consistent with the hypothesis that foreign investors can reduce misallocation by standing in for, and competing with, local credit markets.

We next explore the effect of the reform on prices, exploiting a rare feature in firmlevel datasets: the fact that our panel provides detailed data on each firm's product-mix, as well as information about product-level prices. Since reductions in distortions on input prices should reduce marginal costs for affected firms, firms may pass these gains 
on to consumers in the form of lower prices. Alternatively, the reform may have reduced markups. We find that the reform reduced prices in treated industries by $9 \%$, and this effect was driven by high MRPK firms.

The liberalization policy may have broader effects than reducing firms' wedges on capital inputs. By relaxing financial constraints, the policy may also affect the misallocation of other inputs. If firms need to borrow to pay workers, relaxing financial constraints can also affect labor misallocation. ${ }^{2}$ Motivated by this possibility, we examine the effect of the policy on labor misallocation. Analogous to our approach for capital, we estimate the policy's differential effect on firms with high marginal revenue products of labor (henceforth, "MRPL"). We again find that the reform had greater effects on firms with high MRPL and that wage bills only increased for firms with above median pre-treatment MRPL. For these firms, relative to low MRPL firms, wage bills increased by $32 \%$, and MRPL fell by 35\%. Since high MRPL firms had 96\% higher levels of MRPL prior to the treatment, labor misallocation fell along with capital misallocation following the reform

Finally, combining production function parameter estimates with reduced-form estimates of the policy effect, we generate a lower bound estimate of the aggregate effect of liberalization episodes on the manufacturing industry's Solow residual of $+6.5 \%$. Using our quasi-experimental estimates to adjust for the biases arising from estimating misallocation with cross-sectional data is important. If we attributed all of the baseline variation in the marginal products of inputs to misallocation, we would estimate that the policy increased productivity by $159 \%$. Moreover, this estimate is highly sensitive to the treatment of outliers: winsorizing the top and bottom $15 \%$ of the marginal revenue product measures reduces the estimated policy effect to $10 \%$. Thus, under this approach, the degree to which researchers winsorize can result in a wide range of estimates. In contrast, our preferred lower bound estimate is not sensitive to the treatment of outliers.

This paper contributes to two main literatures, as we discuss below. First, it contributes to the literature quantifying the importance of misallocation for aggregate outcomes (e.g. Restuccia and Rogerson, 2008; Hsieh and Klenow, 2009; Bartelsman, Haltiwanger, and Scarpetta, 2013; Restuccia and Rogerson, 2013; Baqaee and Farhi, forthcoming; David and Venkateswaran, 2019; Sraer and Thesmar, 2020), particularly in the context of developing countries (e.g. Guner, Ventura, and Xu, 2008; Banerjee and Moll, 2010; Collard-Wexler, Asker, and De Loecker, 2011; Oberfield, 2013; Kalemli-Ozcan and Sørensen, 2014). ${ }^{3}$ Second, it contributes to the more specific literature on the effects of financial frictions on misallocation (Buera, Kaboski, and Shin; 2011; Midrigan and Xu, 2014; Moll, 2014; Bai, Carvalho, and Phillips, 2018; Catherine et al., 2018).

Regarding the misallocation literature, a large fraction of the literature has focused

2. For more discussion of this mechanism, see Schoefer (2015) in the U.S. and Fonseca and Doornik (2019) in Brazil.

3. A survey of this literature can be found in Restuccia and Rogerson (2017). 
on measuring the effect of all sources of misallocation on aggregate output by exploiting cross-sectional dispersion in marginal revenue products. The principal advantage of this "indirect approach" (Restuccia and Rogerson, 2017) is that it allows for the estimation of the cost of misallocation without identifying the underlying sources of the distortions, even if the sources are not observable to researchers. However, in this approach, model misspecification and measurement error can inflate estimates of misallocation and bias estimates of the effects of changing misallocation. We make three contributions to this literature. First, since we exploit a liberalization episode that affected only certain industries, we can estimate the effect of deregulation on misallocation using weaker identification assumptions. Our difference-in-differences estimation only requires that measurement error or other unobserved attributes are uncorrelated with the policy to identify changes in input wedges. Second, our approach isolates the changes in distortions produced by a specific policy, foreign capital liberalization. This allows us to isolate the effect of access to the foreign equity market, holding constant access to the foreign debt market and other macroeconomic determinants that might affect the cost of capital. ${ }^{4}$ Third, relative to methodologies that rely on cross-sectional variation to identify wedges, our estimates of the aggregate effects of changing misallocation are less vulnerable to inflation due to measurement error.

By exploiting a natural experiment to identify changes in misallocation and quantify their effects on aggregate productivity, we also relate to Sraer and Thesmar (2020). Sraer and Thesmar (2020) develop a sufficient statistics approach that uses estimates from natural experiments to calculate the counterfactual effects of scaling-up a policy to the entire economy. This is fundamentally different from the object we bound - the aggregate effect of the policy that was actually enacted - which can be bounded with relatively few assumptions about firms' production functions and interactions.

In terms of the literature on capital account liberalization, this paper relates most closely to a recent strand of this literature that has explored how increased foreign financial flows affect domestic firms' productivity and misallocation (Alfaro, Chanda, KalemliOzcan, and Sayek, 2004; Gopinath, Kalemli-Özcan, Karabarbounis, and Villegas-Sanchez, 2017; Varela, 2017; Larrain and Stumpner; 2017; Saffie, Varela, and Yi, 2018). ${ }^{5}$ We add

4. In the context of India, several recent papers have estimated specific characteristics of the Indian economy that might explain the high degree of misallocation observed in the country: the role of property rights and contract enforcement (Bloom et al., 2013; Boehm and Oberfield, 2018); land regulation (Duranton, Ghani, Goswani, and Kerr, 2017); industrial licensing (Chari, 2011; Alfaro and Chari, 2015); privatization (Gupta, 2005; Dinc and Gupta, 2011); reservation laws (Garcia-Santana and Pijoan-Mas, 2014; Martin, Nataraj, and Harrison, 2017; Boehm, Dhingra, and Morrow, 2019; Rotemberg, 2019); highway infrastructure (Ghani, Goswami, and Kerr, 2016); electricity shortages (Allcott, Collard-Wexler, and Connell, 2016) and labor regulation (Amirapu and Gechter, 2019).

5. Varela (2017) shows that financial liberalization can increase productivity, while Saffie, Varela, and Yi (2018) find that financial liberalization also accelerates the reallocation of resources across sectors, promoting the development of service/high-income sectors. On the other hand, Gopinath, KalemliÖzcan, Karabarbounis, and Villegas-Sanchez (2017) find that better access to capital markets can amplify misallocation. 
to this literature in several ways. First, while much of the previous literature exploits country-level variation in access to foreign investment, this paper exploits variation across industries over time within the same country. This allows us to hold the institutional setting constant, while institutional differences are likely to affect cross-country comparisons. Second, since the Indian deregulation only affected foreign investment in equity, it allows us to cleanly isolate the effect of foreign investment in equity on misallocation holding fixed access to foreign debt. ${ }^{6}$

Lastly, we estimate the direction of the effect of deregulating foreign investment on misallocation. Judging by prior findings in the literature, the effect of opening-up to foreign capital on misallocation is a priori unclear. One the one hand, in the context of low-income countries, where formal credit markets are limited and informal credit markets are a poor substitute (Townsend, 1994; Udry, 1994; Banerjee, Duflo, Glennerster, and Kinnan, 2015), credit constraints are likely to be large (Banerjee, Duflo, and Munshi, 2003; Banerjee and Duflo, 2014). Indeed, Anne Krueger, who was deputy managing director of the IMF during the time of the reform we study, wrote that in India, "banks are considered to be very high cost and inefficiently run" and that, "enabling [Indian banks] to allocate credit to the most productive users, rather than by government allocation, would make a considerable contribution to the Indian economy's growth potential" (Krueger et al., 2002). Thus, foreign investment could play a crucial role in reducing misallocation if foreign investors have better screening technologies, or are not bound by historical, political, regulatory or institutional domestic constraints (e.g. Banerjee and Munshi, 2004; Burgess and Pande, 2005; Cole, 2009). On the other hand, foreign investors may also be worse at processing and monitoring soft information, particularly in low-income countries (Detragiache, Tressel, and Gupta, 2008). ${ }^{7}$ Therefore, a final contribution of this paper is showing that foreign capital liberalization policies do reduce misallocation, suggesting that these policies could be a powerful tool for low-income countries to increase aggregate productivity.

The remainder of the paper is organized as follows. Section 2 provides a brief conceptual framework for understanding misallocation and introduces the expression we will use for aggregation. Section 3 describes the data and the context of the policy change. Section 4 discusses our reduced-form empirical strategy, while Section 5 reports our estimates of the average effect of the foreign capital liberalization policy and its heterogeneous effects on firms with high and low capital constraints. Section 6 replicates the analysis for

6. In contrast, Varela (2017) studies the deregulation of capital controls in Hungary, in a context where foreign capital was already integrated and was not affected by the policy. Gopinath, KalemliÖzcan, Karabarbounis, and Villegas-Sanchez (2017) exploit the drop in the interest rate for Southern European countries following the adoption of the Euro, which did not directly change the equity market.

7. In the context of foreign banks' behavior in low-income countries, several studies have found that foreign banks mainly lend to large domestic firms, potentially increasing credit constraints for local firms (e.g. Mian (2006) for Pakistan, Gormley (2010) for India, or Detragiache, Tressel, and Gupta (2008) for a cross-section of countries). 
firms that appear to have high and low labor constraints to test whether the policy also reduced labor misallocation. Section 7 describes the aggregation strategy and reports lower bound estimates of the foreign capital liberalization policies' aggregate effects on the Solow residual. Finally, Section 8 concludes.

\section{Conceptual Framework}

Our conceptual framework section proceeds in two parts. In the first subsection, we sketch a simple framework in general equilibrium that illustrates how our reduced-form results can shed light on changes in misallocation. In the second subsection, we introduce the expression that we will use to quantify the aggregate effects of changes in misallocation.

\subsection{Misallocation and Reduced-Form Predictions}

We follow standard practice in the literature and model misallocation via wedges on the prices of inputs. Intuitively, the wedges can be thought of as explicit taxes or implicit taxes which implement a given (potentially inefficient) allocation in the decentralized Arrow-Debreu-McKenzie economy. Thus, the price paid by a firm $i$ for an input $x$ is $\left(1+\tilde{\tau}_{i}^{x}\right) p^{x}$, where $x \in\{K, L, M\}$ and $K, L$, and $M$ denote capital, labor, and materials, respectively. The price of input $x$ is $p^{x}$, and $\tilde{\tau}_{i}^{x}$ is the additional wedge a firm pays for the input over the market price. The wedge $\tilde{\tau}_{i}^{x}$ can be negative, indicating that a firm is subsidized, or positive, indicating that the firm pays a tax. A single-product firm's profit function is

$$
\pi_{i}=p_{i} f_{i}\left(K_{i}, L_{i}, M_{i}\right)-\sum_{x \in\{K, L, M\}}\left(1+\tilde{\tau}_{i}^{x}\right) p^{x} x_{i}
$$

where $f_{i}\left(K_{i}, L_{i}, M_{i}\right)$ is the firm's production function, which exhibits diminishing marginal returns in each input.

A cost-minimizing firm will consume an input $x_{i}$ until that input's marginal revenue returns $p_{i} \partial f_{i}\left(K_{i}, L_{i}, M_{i}\right) / \partial x_{i}$ are equal to the cost

$$
p_{i} \frac{\partial f_{i}\left(K_{i}, L_{i}, M_{i}\right)}{\partial x_{i}}=\mu_{i}\left(1+\tilde{\tau}_{i}^{x}\right) p^{x}
$$

where $\mu_{i}$ is the mark-up or output wedge. ${ }^{8}$ Then, define the combined wedge $1+\tau_{i}^{x}=$ $\mu_{i}\left(1+\tilde{\tau}_{i}^{x}\right)$. The marginal revenue product of input $x$ is proportional to the (combined)

8. Technically, if firm $i$ has pricing power, then the marginal revenue product of $x$ (MRPX) is better defined as $p_{i} \partial f_{i}\left(K_{i}, L_{i}, M_{i}\right) / \partial x_{i}+\partial p_{i} / \partial x_{i} f_{i}\left(K_{i}, L_{i}, M_{i}\right)$. However, in the literature, MRPX typically only refers to the first summand because it is dispersion in the first summand that causes misallocation. Thus, we follow the convention of the literature at the cost of abusing terminology. 
wedge $\tau_{i}^{x}$. Therefore, firms with higher combined input wedges $\tau_{i}^{x}$ (capital, labor or any other) will have higher marginal revenue products on this input (henceforth, "MPRX").

We now generate partial equilibrium predictions that we can use to test for a reduction in misallocation in the data. A decrease in the misallocation of input $x$ occurs when the wedge $\tau_{i}^{x}$ declines for a firm whose wedge is high relative to other firms. A decline in the wedges of firms with relatively high initial $\tau_{i}^{x}$ will have several effects. The most direct effect is that, since $\tau_{i}^{x}$ falls, the measured MRPX should also fall for these firms. Second, firms with high wedges will increase their use of $x$. Finally, the increase in input $x$ (say capital) will increase the marginal revenue products of the other inputs, which will incentivize firms to also increase their demand for these other inputs (e.g. labor or materials). As a result of higher input use, these firms will produce more and earn higher revenues. Thus, if the policy reduces capital misallocation by reducing the wedges of firms with high $\tau_{i}^{k}$, we should expect to find that the policy increases capital, labor, and sales for these firms and decreases MRPK. Moreover, these effects should be differentially stronger in previously input constrained (high MRPK) firms relative to less constrained firms. ${ }^{9}$

\subsection{Framework for Quantifying Effects on the Solow Residual}

To quantify the aggregate effect of reducing misallocation on manufacturing productivity, following much of the literature, we proxy for changes in aggregate productivity with changes in the Solow residual, which measures net output growth minus net input growth. Let net output of good $i$ be $c_{i}=y_{i}-\sum_{j \in I} y_{i j}$, where $y_{i}$ is the output of firm $i$ and $y_{i j}$ are the inputs used by firm $j$ of the output of $i$. The change in the industry's net output is defined as $\Delta C_{I}=\sum_{i \in I} p_{i} \Delta c_{i}$. This is the total change in net quantities valued using fixed prices. The Solow residual, $\Delta$ Solow $_{I}$ (output growth net of input growth) in discrete time is

$$
\Delta \text { Solow }_{I}=\Delta \log C_{I}-\sum_{j \notin I} \frac{\sum_{i \in I} p_{j} y_{i j}}{\sum_{i \in I} p_{i} c_{i}} \Delta \log \sum_{i \in I} y_{i j} .
$$

The summation $\sum_{j \notin I}$ sums over firms that supply intermediate goods to the manufacturing sector but are not themselves in manufacturing, while the summation $\sum_{i \in I}$ sums over firms in the manufacturing sector. Thus, $\Delta \log C_{I}$ measures the change in output due to the policy (differencing out outputs that are re-used as inputs), while subtract$\operatorname{ing} \sum_{j \notin I} \frac{\sum_{i \in I} p_{j} y_{i j}}{\sum_{i \in I} p_{i} c_{i}} \Delta \log \sum_{i \in I} y_{i j}$ differences out changes in inputs purchased from outside the manufacturing sector. Intuitively, the Solow residual measures the change in output valued using current market prices and differences out the growth in inputs valued using

9. In our framework, TFPR is not necessarily proportional to the product of MRPK and MRPL as in Hsieh and Klenow (2009). This is because our framework is more general and does not assume constant returns to scale. 
those same prices. Thus, in an accounting sense, it controls for input growth due to the policy.

In general, as demonstrated by Petrin and Levinsohn (2012) and Baqaee and Farhi (2019), a first order approximation of the change in the Solow Residual of industry I over time is given by:

$$
\Delta \text { Solow }_{I, t} \approx \sum_{i \in I} \lambda_{i} \Delta \log A_{i}+\sum_{\substack{i \in I \\ x \in\{k, l, m\}}} \lambda_{i} \alpha_{i}^{x} \tau_{i}^{x} \Delta \log x_{i}
$$

where $\alpha_{i}^{x}$ is the output elasticity of $i$ with respect to input $x, \lambda_{i}$ is each producer's sales as a share of manufacturing's net output, and $\Delta \log A_{i}$ is the firm-specific change in total factor productivity. This expression allows us to convert firm-level effects, which are in different units depending on the goods being produced, into aggregate effects. A derivation of this expression is provided in Appendix A and shows that this expression does not require any assumptions about returns to scale, cross-good aggregation, or the shape of input-output networks. As we will explain in Section 7, equation (2) will allow us to exploit our reduced-form estimates to bound the aggregate effect of the policy change on the Solow residual.

\section{Data and Policy Change}

In this section, we describe the context of the financial liberalization policies in India and the data used in this paper.

\subsection{Indian Foreign Investment Liberalization}

Following its independence, India became a closed, socialist economy, and most sectors were heavily regulated. ${ }^{10}$ However, in 1991, India experienced a severe balance of payments crisis, and in June 1991, a new government was elected. Under pressure from the IMF, the World Bank, and the Asian Development Bank, which offered funding, the Indian government engaged in a series of structural reforms. These reforms led India to become more open and market-oriented. In addition to initiating foreign capital reforms in this period, India also liberalized trade (e.g. Topalova and Khandelwal, 2011; Goldberg, Khandelwal, Pavcnik, and Topalova, 2010) and dismantled extensive licensing requirements (e.g. Aghion, Burgess, Redding, and Zilibotti, 2008; Chari, 2011).

Before 1991, most industries were regulated by the Foreign Exchange Regulation Act (1973), which required every instance of foreign investment to be individually approved by the government, and foreign ownership rates were restricted to below $40 \%$ in most

10. See Panagariya (2008) for a thorough review of the Indian growth experience and government policies. 
industries. With the establishment of the initial liberalization reform in 1991, foreign investment up to $51 \%$ of equity in certain industries became automatically approved. ${ }^{11}$ In the following years, different industries liberalized at different times, increasing the cap on foreign investment and allowing for automatic approval. Based on our discussions with civil servants in charge of implementing financial liberalizations, the choice of which industries to liberalize may have been driven by the lack of clear foreign competitors that could enter the country via the FDI route and quickly wipe out local competition. ${ }^{12}$ We study the effects of financial liberalization episodes that occurred after 2000, after the main period of reform in the 1990s. This is both due to data availability, as described below, and to avoid conflating the effects of the financial liberalization reforms with other ongoing reforms.

To study the effects of foreign investment liberalization, we hand-collected data on the timing of disaggregated industry-level policy changes from different editions of the Handbook of Industrial Policy and Statistics. We match this data to industries at the 5digit NIC level. An industry is coded as having been treated if a policy change occurred that allowed automatic approval for investments up to at least $51 \%$ of capital (though, in some cases, the maximum is higher). We then merge this data at the industry-level with the firm-level dataset described below.

\subsection{Firm and Product-Level Data}

Our firm-level data comes from the Prowess database compiled by the Centre for Monitoring the Indian Economy (CMIE) and includes all publicly traded firms, as well as a large number of private firms. Unlike the Annual Survey of Industries (ASI), which is the other main source of information used to study dynamics in the Indian manufacturing sector, Prowess is a firm-level panel dataset. ${ }^{13}$ The data is therefore particularly wellsuited for examination of how firms adjust over time in reaction to policy changes. The dataset contains information from the income statements and balance sheets of companies comprising more than $70 \%$ of the economic activity in the organized industrial sector of India and $75 \%$ of all corporate taxes collected by the Government of India. It is thus representative of large and medium-sized Indian firms. We retrieve yearly information about sales, capital stock (measured as physical assets), consumption of raw materials and energy, and compensation of employees for each firm.

To estimate the effect of the reform on prices, we take advantage of one rare feature

11. This policy is described by Topalova (2007), Sivadasan (2009), and Chari and Gupta (2008).

12. This would explain, for instance, why even within 3-digit industries, some industries were liberalized such as "Manufacture of rubber tyres and tubes for cycles and cycle-ricks" but not the manufacture of rubber more broadly.

13. The ASI is collected at the plant-level and does not include information on whether plants are owned by the same firm, making it impossible to detect changes in misallocation across firms due to opening or closing establishments. 
in firm-level datasets that is available in Prowess: the dataset reports both total product sales and total quantity sold at the firm-product level, allowing us to compute unit prices and quantities. This peculiar feature is due to the fact that Indian firms are required by the 1956 Companies Act to disclose product-level information on capacities, production, and sales in their annual reports. A detailed discussion of the data can be found in Goldberg, Khandelwal, Pavcnik, and Topalova (2010). The definition of a product is based on Prowess's internal product classification, which is in turn based on India's national industrial classification (NIC) and contains 1,400 distinct products. Using this information, we can calculate the unit-level price for each product, which we define as total unit sales over total unit quantity. This allows us to also construct a separate panel of product-level output and prices from 1995-2015. ${ }^{14}$

\subsection{Local Financial Development Data}

To examine whether financial liberalization's effects depend on local financial development, we also collect state-level banking data. India is a federal country with a banking market that is largely regulated at the state-level, creating important disparities in the degree of the development of the local credit market across states (e.g. Burgess and Pande, 2005; Vig, 2013). To take advantage of this geographic variation, we hand-collected data at the state-level from each of the pre-reform years (1995-2000) on the credits of all scheduled commercial banks from the Reserve Bank of India.

Over the study period, the administrative organization of districts and states in India changed several times due to the formation of new states (e.g. Jharkhand was carved out of Bihar in November 2000) or the bifurcation of existing districts within a state. We keep the administrative organization of states fixed as of 1999. This is straightforward since the vast majority of cases where a new state is created are because that state was carved out of only one existing state. Our state-level measures encompass 25 out of 26 Indian states and four out of seven union territories. Altogether, this data covers $91.5 \%$ of net domestic product and $99 \%$ of credit.

\subsection{Combined Data Sets}

To arrive at our final datasets for analysis, we merge the firm-level and product-level panel data with the industry-level policy data and state-level financial development data.

As is common in the literature estimating production functions, we restrict our analysis to manufacturing firms. We further restrict the sample to observations from the period

14. One limitation of this dataset is that firms choose which type of units to report, and units are not standardized across firms or within-firms over time. Thus, when we want to analyze the effects of policy changes on prices/output and there is not enough information to reconcile changes in unit types within a firm-product over time, we are forced to drop the set of observations associated with a firm-product. As a result, we omit 5,077 firm-product-year observations. 
between 1995 and 2015. Restricting the sample to 1995-2015 has two advantages. First, focusing on this later period avoids potential bias from other liberalization reforms during the early-1990s, the main Indian liberalization period. While liberalization occurred for $45 \%$ of manufacturing firms in the data, by restricting our sample to observations after 1995, we only exploit policy variation for the $9 \%$ of manufacturing firms who experienced foreign capital liberalization in the 2000s. Second, although Prowess, technically starts in 1988, its coverage in the first few years is limited and grows substantially over time. In 1988, Prowess only included 1,057 firms total, but it had grown to 7,061 firms by the beginning of our study period in 1995. In contrast, from 1995 onward, during our study period, the coverage of the database is more stable, with similar numbers of firms observed across subsequent years (7,526 firms observed in 1996, 7,286 in 1997, and 7,717 in 1998). ${ }^{15}$

Additionally, to allow for a longer pre-policy period over which to calculate MRPK and classify MRPK as high or low, as described below, we drop a very small number of observations that experienced a liberalization in 1998. This amounts to 104 total firm-year observations (roughly $4-5$ per year) or $0.16 \%$ of the sample. Appendix Table A1 provides a list of the different industries in the manufacturing sector affected by the deregulation during the remaining sample. As the table shows, after dropping the 1998 liberalization, the only remaining liberalization episodes occurred in 2001 and 2006.

Finally, we restrict the sample to the set of firms for whom we can compute marginal revenue products of capital and labor (MRPK and MRPL) prior to the earliest policy change in 2001. These pre-policy change measures are needed to estimate the effects of the policy on misallocation. Thus, we restrict the sample to firms observed before 2001 with non-missing, positive data on both assets and sales. ${ }^{16}$ These restrictions leave us with 4,927 distinct firms, across 340 distinct 5-digit industries, for a total of 63,950 observations.

Table 1 documents summary statistics for the final firm-level sample used in our analysis. As the table shows, classifying firms based on the owner's name, we find that the typical firm in our analysis is a privately-owned domestic firm (57\%), while $5 \%$ of firms are private, foreign-owned firms, and $4 \%$ are state-owned. The table also shows that $9 \%$ of firms are in industries that experienced the policy change between 1995 and 2015 .

15. This likely reflects the fact that the first wave of liberalizing reforms also standardized financial reporting in the mid-1990s.

16. This is the minimal requirement to calculate MRPK. As we document in the next subsection, we use two methods to estimate marginal revenue returns to capital. The least data intensive method exploits the fact that, under Cobb-Douglas production functions, sales divided by capital will be proportional to MRPK within an industry as long as $\alpha_{j}^{k}$ is the same for all firms in that industry. 


\section{Empirical Strategy}

\subsection{Classifying Firms as High or Low MRPK}

To estimate whether foreign investment liberalization reduces misallocation, we follow the predictions in our conceptual framework and test if the reform has a differential effect on firms with high and low MPRK. For our main analyses, we use two methods to measure firms' MRPK.

As is standard in the production function estimation literature, ${ }^{17}$ we assume that firms have Cobb-Douglas production functions:

$$
Y_{i j t}=A_{i j t} K_{i j t}^{\alpha_{j}^{k}} L_{i j t}^{\alpha_{j}^{l}} M_{i j t}^{\alpha_{j}^{m}}
$$

where $i$ denotes a firm, $j$ denotes a 2-digit industry, and $t$ denotes a year. $Y_{i j t}, K_{i j t}, L_{i j t}$, and $M_{i j t}$ are measures of output, assets, the wage bill, and materials, and $A_{i j t}$ is the firmspecific unobserved productivity. We measure these parameters with deflated Ruppee amounts, so that $Y_{i j t}$ is proxied with deflated sales. ${ }^{18}$ As we observe sales rather than quantities in our main specifications, our production function estimates are in revenue terms.

Our first and primary method for estimating MRPK takes advantage of the fact that, under the revenue Cobb-Douglas production function, $M R P K=\frac{\partial Y_{i t}}{\partial K_{i t}}=\alpha_{j}^{k} \frac{Y_{i t}}{K_{i t}}$. Thus, $\frac{Y_{i t}}{K_{i t}}$ provides a within-industry measure of MRPK, under the assumption that all firms in an industry share the same $\alpha_{j}^{k}$. This is our preferred method because it imposes the fewest data requirements, and therefore, allows us to use the largest possible sample for estimation.

As an alternative, we also use the method of Levinsohn and Petrin (2003) (henceforth "LP"), using the GMM estimation proposed by Wooldridge (2009), to estimate the parameters of the production function at the 2-digit industry-level. ${ }^{19}$ The LP method assumes the same Cobb-Douglas production function as in equation (3) and estimates its parameters using a control function approach. Once we estimate the full set of parameters of the production functions, MRPK is given by the derivative of the production function

17. Duranton, Ghani, Goswani, and Kerr (2017) describe the variety of methods used to estimate production functions and the revenue returns to capital and labor.

18. We use deflators for India made available by Allcott, Collard-Wexler, and Connell (2016) for the period 1995-2012, and we manually extended the price series to 2015. Revenue is deflated using threedigit commodity price deflators. The materials deflators are measures of the average output deflator of a given industry's suppliers using the 1993-4 input-output table. The capital deflator is obtained using an implied national deflator.

19. This exercise assumes that wedges are not correlated with firms' input choices. An example of such a correlation is a variable markup. In Section 5, we replicate our results using the subsample of firms where unit price data for consistent unit measures is available. This allows us to estimate quantity production functions, rather than revenue production functions, circumventing issues that arise from variable markups. Using quantity production functions, we arrive at very similar results. 
with respect to $K_{i t}$. This method requires observing $L_{i t}$ and $M_{i t}$ in addition to $K_{i t}$ and $Y_{i t}$. Using the LP method, we also estimate TFPR, which is equivalent to $\tilde{p}_{i j t} \times T F P$, where $\tilde{p}_{i j t}$ is the firm's deflated price. As the production function is in revenue terms, this is accomplished by estimating $A_{i j t}{ }^{20}$ By estimating the effect of the reform on TFPR, we will be able to determine if foreign capital liberalization affects within-firm productivity with the caveat that changes in prices that are not captured by industry-level deflators will also affect TFPR.

To determine whether firms had a high or low MRPK prior to the reform, we average each firm's measures of MRPK over 1995-2000 (the last year prior to the first policy change). We then classify a firm as capital constrained (high MRPK) if it is above the 4-digit level industry median for the averaged measure. Since we have two measures of MRPK, this produces two measures of whether a firm is capital constrained or not.

Before turning to our main econometric specifications, we report the baseline levels of misallocation in the Indian manufacturing sector based on the cross-sectional dispersion of MRPK. However, we caution that dispersion in the cross-sectional distribution of MRPK is likely to be upwardly biased by measurement error or misspecified production functions. Figure 1 reports the distribution of $\log (\mathrm{MRPK})$ as measured using the LP methodology during 2000. ${ }^{21}$ Based on this measure, there appears to be substantial misallocation. A firm at the 90th percentile has a $\log (\mathrm{MRPK}) 22$ times greater than that of a firm at the 10th percentile.

\subsection{Econometric Specification}

\section{Firm-level Outcomes}

Main Specification. To determine whether the financial liberalization reduces misallocation, we test the predictions from the conceptual framework. If liberalization reduces misallocation, it will have heterogeneous effects on firms within the same industry. More specifically, if firms that are more capital constrained ex ante experience reductions in their capital frictions, they will invest more in response to the reform. Our strategy exploits panel data, rather than relying on cross-sectional variation, allowing us to identify within-firm changes in distortions in treated versus untreated industries and differentiate out all the time invariant, unobserved heterogeneity across producers that may bias

20. One concern in our setting is that multi-product firms produce goods in multiple industries, leading to bias when we estimate production function parameters at the industry-level. We use the firm-level industry identifiers provided by Prowess to assign firms to industries, and this issue is partially mitigated by the fact that subsidiaries of large conglomerates in different industries appear as different observations in the data.

21. Our primary measure $(\mathrm{Y} / \mathrm{K})$ only allows us to compare MRPK within-industries, as opposed to across industries. Thus, measures of MRPK produced by the $\mathrm{Y} / \mathrm{K}$ method cannot be used to obtain a cross-sectional measure of misallocation. 
estimates of the level of MRPK dispersion. ${ }^{22}$

To asses the effect of liberalization on the reallocation of resources within industries, our main regression equation is

$$
y_{i j t}=\beta_{1} \text { Reform }_{j t}+\beta_{2} \text { Reform }_{j t} \times I_{i}^{\text {High MRPK }}+\mathbf{\Gamma X}_{\mathbf{i t}}+\theta_{i}+\delta_{t}+\epsilon_{i j t}
$$

where $i$ denotes a firm, $j$ denotes an industry, $t$ denotes a year, and $y_{i j t}$ is the outcome variable of interest, consisting of the logs of physical capital, the total wage bill, sales, TFPR and MRPK. Reform ${ }_{j t}$ is an indicator variable equal to one if foreign investment has been liberalized in industry $j$, and in the most parsimonious specification, $\mathbf{X}_{\mathbf{i t}}$ consists of firm age fixed effects. $I_{i}^{H i g h M R P K}$ is an indicator variable equal to 1 if a firm has a high pre-reform MRPK according to our measures defined in Section 4.1. Because the reform occurred at the industry level, we twoway cluster our standard errors at the 4-digit industry and year level to account for any serial correlation that might bias our standard errors downward. ${ }^{23}$

The coefficient of interest is $\beta_{2}$, which captures the differential effect of the reform on ex ante capital constrained firms relative to unconstrained firms. $\beta_{2}>0$ implies that the dependent variable increases differentially for capital constrained firms relative to unconstrained firms in industries that have opened up to foreign capital relative to industries that have not opened up. As described in Section 2, when the outcome variable is MRPK, $\beta_{1}$ captures changes in low MRPK firms' capital wedges, and $\beta_{1}+\beta_{2}$ captures total changes in high MRPK firms' capital wedges due to the reform.

If we were calculating the level of capital misallocation using cross-sectional data, a standard approach would be to use an estimate of the variance of MRPK as a proxy for the dispersion of the wedges. This estimate would sum over both the variance of the wedges and the variance of measurement error, leading to inflated estimates of the dispersion of the wedges. In contrast, estimates of the change in wedges in equation (4) are unlikely to be inflated by measurement error in MRPK. Focusing on the left side of the equation, if measurement error in MRPK is uncorrelated with the treatment variable, measurement error in the outcome variable will not bias the results. Turning to the right side, idiosyncratic measurement error in MRPK may bias our estimate of $\beta_{2}$ if it leads to error in the coding of $I_{i}^{\text {High } M R P K}$. This measurement error would lead some firms that are

22. An alternative approach to estimating the effects of the policy on misallocation would be to estimate the difference-in-differences regressions at the industry-level with the industry-level variance of MRPK as the outcome measure. We do not follow this approach for two reasons. First, the treatment is at the 5-digit industry-level, and 5-digit industries are very fine. The average 5-digit industry-year cell has only 10 firm-year observations, and $10 \%$ of firm-year observations are in 5-digit industry-year cells with 4 or fewer observations. Thus, in many cases, we cannot credibly estimate variance at the 5-digit industry-year level. Second, as we will show in Section 7, the firm-level difference-in-differences estimates will exactly map to the objects needed to measure changes in the Solow residual.

23. Our treatment variable is coded at the 5-digit industry-level, but we cluster at the 4-digit level to account for possible correlations in treatment statuses across more closely related industries. 
actually constrained to be coded as unconstrained, while some unconstrained firms will be coded as constrained. But, as long as the true effect of the policy is to reduce MRPK more for ex ante high MRPK firms, misclassification will lead to attenuation bias, biasing our estimate of $\beta_{2}$ toward zero. Since $\beta_{2}$ captures the change in high MRPK firms' capital wedges, this would lead us to underestimate the change in these firms' wedges due to the policy. Thus, measurement error would make us underestimate rather than overestimate the effect of the policy on misallocation.

Our main regression specifications also account for several other sources of bias beyond measurement error. Firm fixed effects $\left(\theta_{i}\right)$ absorb all unobserved time-invariant heterogeneity across firms and remove biases that could occur if, for example, more productive industries are more likely to be liberalized or if more productive firms are more likely to enter liberalized industries. Time fixed effects $\left(\delta_{t}\right)$ absorb any macroeconomic fluctuations or country-wide reforms that may be correlated with the deregulation episodes.

To test for within industry reallocation, we can control directly for the baseline effect of being in a deregulated industry with the variable Reform $_{j t}$ and still estimate $\beta_{2}$, the relative effect of the policy on inputs and wedges for high MRPK firms. This accounts for any industry-level time trends or shocks that differentially affect deregulated and non-deregulated industries. In our most conservative specification, we control non-parametrically for industry-level unobserved shocks/time trends by including 5-digit industry-by-year fixed effects. In this specification, even if the Indian government liberalized industries that were growing more quickly earlier, $\beta_{2}$ would not be biased as long as high MPRK firms were not growing relatively more within these industries. When testing for whether the policy reduced misallocation, the identifying assumption for equation (4) is therefore milder than in the classic difference-in-differences framework, which would require that the liberalization policy was uncorrelated with industry-level time trends.

Assessing Parallel Trends. Our estimates could still be biased if the difference between high and low MRPK firms would have grown at a different rate in treated vs untreated industries in the absence of the policy. This might occur if the Indian government targeted the policy toward industries where misallocation was already decreasing, although it is not clear why this would be the case. We test for this source of bias by estimating and plotting the year-by-year relative treatment effect for high MRPK firms in event study graphs. If the outcomes of high MPRK firms were indeed changing faster in treated industries relative to untreated industries prior to the policy change, we should see an effect of belonging to an industry that would be deregulated in the future on high MPRK firms prior to the policy change. The yearly differential effects of the policy are 
obtained by estimating the following equation:

$$
\begin{gathered}
y_{i j t}=\sum_{g} \beta_{1, g} \text { Reform }_{j t} \times I_{i t}^{g}+\sum_{g} \beta_{2, g} \text { Reform }_{j t} \times I_{i}^{\text {High MRPK }} \times I_{i t}^{g} \\
+\mathbf{\Gamma X}_{\mathbf{i t}}+\theta_{i}+\delta_{t}+\epsilon_{i j t}
\end{gathered}
$$

where an industry's policy change is normalized to take place in period 0 , and $\sum_{g}$ is a summation over the years that firms were observed before and after the policy event. $I_{i t}^{g}$ is an indicator variable equal to 1 if in year $t$ a firm was observed $g$ years after the policy event. Then, our event study graphs plot the set of coefficients $\beta_{2, g}$, which estimate the relative effect of being in a treated industry on a high MPRK firm (relative to a low MRPK firm) for each year.

Average Industry-level Policy Effect. Finally, we also estimate the effect of the reform on the average firm in an industry using a classic difference-in-differences strategy of the following form:

$$
y_{i j t}=\beta_{1} \text { Reform }_{j t}+\mathbf{\Gamma X}_{\mathbf{i t}}+\theta_{i}+\delta_{t}+\epsilon_{i j t} .
$$

In this case, the coefficient of interest, $\beta_{1}$, measures the average effect of being in an industry that has liberalized, relative to other industries, and is identified only by comparing changes in outcomes for the liberalized firms between the pre and post-periods to the changes for non-liberalized firms.

\section{Product-level Outcomes}

To assess the heterogeneous effects of the policy on unit prices and quantities at the product-firm-year level, we estimate:

$$
y_{i p j t}=\beta_{1} \text { Reform }_{j t}+\beta_{2} \text { Reform }_{j t} \times I_{i}^{\text {High MRPK }}+\mathbf{\Gamma X}_{\mathbf{i t}}+\theta_{i p}+\delta_{t}+\epsilon_{i p j t}
$$

with the additional subscript $p$ denoting a product, and the fixed effect $\theta_{i p}$ denoting a firm-by-product fixed effect. The remaining notation and terms are unchanged, with $\beta_{2}$ now capturing the differential effect of the reform on log unit prices and log quantity produced for high MRPK firms, while $\beta_{1}$ identifies the effect for low MRPK firms. We also estimate the effect for the average firm, as in equation (6), by dropping the interaction term.

The inclusion of firm-by-product fixed effects $\left(\theta_{i p}\right)$ means that we estimate the effect of the reform within firm-product pairs and account for unobserved time-invariant differences across products. In particular, it ensures that $\beta_{2}$ is not biased by firms adding new 
products or dropping old ones. Additionally, the fixed effects also account for the fact that the definition of a unit is different across firms or products.

\section{Results}

\subsection{Average Effects}

Table 2 reports the effect of the reform on the average firm (equation (6)). The estimates indicate that the liberalization policy had positive effects on the average firm's development. For the average firm, revenues increased by $22 \%$ (column 1), and capital increased by $29 \%$ (column 2), both significant at the $1 \%$ level. The point estimate for the total wage bill is positive but not statistically significant, while the marginal revenue product of capital (MRPK) decreases by an insignificant $18 \%$. The reform does not change the average firm's TFPR. However, we caution that this identification strategy could underestimate gains in firm-level productivity, since TFPR is a function of TFP and the deflated price. If prices fell in response to the policy (something we will find evidence for in Section 5.3), TFPR could fall or remain unchanged even if TFP increased.

\subsection{Differential Effects by Ex Ante MRPK}

\section{Baseline Specification}

Table 3 reports the estimates of the heterogeneous effects of the policy from equation (4), our main estimating equation. Panel A uses our primary method for classifying whether firms are capital constrained or not, while Panel B reports the results using the LP method. Since both methods produce economically large and statistically significant effects, in our discussion of the results, we focus on the case where capital constrained firms are identified using the $Y / K$ method to simplify exposition.

Following the liberalization, capital constrained firms (high MRPK firms) generate relatively greater revenues by $18 \%$ (column 1). Higher revenues are made possible by the fact that capital constrained firms invest more, with their physical capital increasing by $60 \%$ (column 2). ${ }^{24}$ Higher investment does not crowd-out labor. Capital constrained

24. One alternative explanation for this finding comes from the idea that, if our classification of high and low MRPK firms is affected by measurement error, firms with large negative measurement error in their capital will be classified as high MRPK. Then, if the policy change led firms to improve their reporting, perhaps to attract foreign investment, high MRPK firms would appear to increase their capital due to the policy. However, this is unlikely to be driving the results. First, we would then expect sales to decrease for high MRPK firms following the policy change due to the same mechanism, while the opposite is the case. Second, we will show the same pattern of effects for output, as well as capital and revenues. Output is measured separately from sales and capital at the product-level, and its idiosyncratic measurement error should be independent. 
firms also experience a relative increase in their wage bills by $26 \%,{ }^{25}$ suggesting that there may be important complementarities between capital and labor in India. ${ }^{26}$ We will explore whether the reform also reduced labor misallocation in Section 6. Additionally, among the ex ante capital constrained firms, the policy also reduced MRPK by $43 \%$. Given that, prior to the reform, high MRPK firms had a MRPK 3.8 times greater than low MRPK firms, the reform led to an important decline in the dispersion of MRPK. Taken together, our effects imply that the liberalization of foreign capital substantially reduced misallocation.

While the reform changed the allocation of inputs across the firms, we again find no evidence that they affected within-firm productivity, as proxied by TFPR (column $5)$. These findings seem to suggest that the liberalization of foreign capital mainly led to efficiency gains due to the reallocation of inputs within industries, rather than an acceleration of productivity growth within firms. ${ }^{27}$

Next, to assess whether these results are driven by pre-trends, we plot the event study graphs described by equation (5) for our key outcomes of interest. Figure 2 reports these results for the logs of capital, sales, the wage bill, and MRPK. Two facts are noteworthy.

First, for all of these outcomes, being treated by the policy had no differential effect on high MRPK firms before the policy was adopted, providing visual evidence that pretrends were parallel. This graph can also be thought of as providing a placebo test, showing that being in a treated industry had no significant effect on high MRPK firms relative to low MRPK firms before the policy was implemented. The lack of correlation between firm outcomes and the reform prior to the year of deregulation also implies that our results are not driven by mean reversion. If that was the case, we should observe a decline in MRPK prior to the policy change.

Second, the effect of the liberalization on the different firm outcomes is progressive over time, consistent with the idea that the reallocation of resources (such as the adjustment of worker flows and adaptation of production tools) is likely slow moving, particularly in India (e.g. Topalova, 2010) . In addition, some of the reallocation we observe might also come from competitive effects, where the relaxation of credit constraints allows firms with higher returns to capital to expand at the expense of the less efficient/ex ante less constrained firms, potentially leading to important economic gains (Foster, Haltiwanger, and Syverson, 2008). We also expect this phenomenon to be progressive and only fully

25. Unfortunately, Prowess only reports the total wage bill rather than the number of employees. Thus, we cannot determine whether the increase in wage bill is due to greater labor productivity due to increased capital, a change in employee skill, or to more employees being hired.

26. The existence of these complementarities is consistent with evidence in Fonseca and Doornik (2019) in a different developing country, Brazil.

27. This finding my be surprising given the results in Bollard, Klenow, and Sharma (2013), who find that most of economic growth in the earlier period in India could be attributed to within firm changes in productivity and not reallocation on inputs. However, Nishida, Petrin, Rotemberg, and White (2017) show that this conclusion strongly depends on the form of the production function and that they are likely underestimating the contribution of reallocation to aggregate growth. 
observable after some time has passed.

\section{Importance of the Local Banking Market}

Our results so far show that opening-up to foreign capital allows capital constrained firms to invest more and grow faster. If foreign capital is acting as a substitute for a more efficient domestic banking sector, a natural implication is that firms located in areas with more developed local banking markets prior to the reform should benefit less from the reduction in credit constraints. We directly test this hypothesis by creating a variable Local Credit Market Development ${ }_{s}$, defined as the log average over 1995-2000 of all bank credit in state $s$. We then interact this measure with all the single and cross-terms in equation (4). The variable is de-meaned to restore the baseline effect on $I_{i}^{\text {High MRPK }} \times$ Reform $_{j t}$. The coefficient of interest is the coefficient for the triple interaction $I_{i}^{\text {High MRPK }} \times$ Reform $_{j t} \times$ Local Credit Market Development $_{s}$, which captures the differential effect of the policy on capital constrained firms located in more developed local banking markets.

Table 4 reports the results. For revenues, capital, and wages, the interaction $I_{i}^{H i g h} M R P K \times$ Reform $_{j t} \times$ Local Credit Market Development $_{s}$ is negative and significant at the $1 \%$ level. For MPRK, the triple interaction is positive and significant. Taken together, these results imply that capital wedges fell more following the reform for high MRPK firms located in less financially developed states.

In addition to being statistically significant, the magnitudes of the heterogeneous effects are economically meaningful. If we focus on the change in the marginal revenue products of capital (column 4), ex ante high MRPK firms located in a state at the $75^{\text {th }}$ percentile of the bank credit distribution experienced a decrease in MRPK of $34 \%(-0.44+(0.08 \times-0.71))$. In contrast, high MRPK firms located in a state at the $25^{\text {th }}$ percentile of the bank credit distribution experienced a decrease in MPRK of $51 \%$ $(-0.44+(0.08 \times 1.37))$. Thus, the reduction at the $25^{\text {th }}$ percentile is $50 \%$ larger than the one at the $75^{\text {th }}$ percentile.

The fact that the effects of the policy were smaller in states where credit constraints were a priori lower further confirms that opening up to foreign capital relaxed credit constraints and allowed previously constrained firms to invest more.

\subsection{Product-level Outcomes: Quantities and Prices}

\section{Prices}

We next turn to the effect of the reform on prices. Opening-up to foreign capital can reduce prices for two reasons. If liberalization reduced the wedges on capital for high MRPK firms, these firms' marginal costs would fall. Lower marginal costs may be passed 
on to consumers in the form of lower prices. In addition, by allowing credit constrained firms to invest more and expand, the reform could also increase competition in the product market, leading firms to reduce their mark-ups and cut their prices.

To examine whether prices are affected, we estimate equation (7) with log unit price as the outcome variable. Columns $1-3$ of Table 5 report the results. On average, the reform reduces prices by $9 \%$ (column 1 ). When we disaggregate this average effect, we find that the reduction is concentrated among the high MRPK firms (column 2) according to the $Y / K$ classification of high MRPK. The alternative classification of MRPK yields a similar pattern, although the estimate of the differential effect is smaller.

The decrease in prices we observe for capital constrained firms following the liberalization may partially explain the fact that the policy change had little effect on our measures of revenue productivity (TFPR). Even if the policy did increase firm-level productivity (TFP), this may not be reflected by increases in TFPR if prices fell.

\section{Quantities}

We also test whether the increase in revenues caused by the reform was accompanied by a product-level increase in output. An increase in output for high MRPK firms does not need to occur mechanically in the data, since the results we have shown previously are for firm-level sales. Instead, separately reported unit-level sales and prices are used to calculate output. To estimate the effect of the policy on output, we estimate equation (7) with log units produced as the outcome. The last three columns of Table 5 report the results, with column 4 reporting the average effects and columns 5 and 6 reporting heterogeneous effects using the $\mathrm{Y} / \mathrm{K}$ and LP definitions, respectively. On average, output increases by $23 \%$, with larger effects on capital constrained firms. Among high MRPK firms, quantity produced increases by $27 \%$, while low MRPK firms experience an increase of $14 \%$.

Since our observations are at the product-firm-year level, and the specification controls for firm-by-product fixed effects, the effect of the liberalization on quantities is estimated exclusively on the intensive margin. That is, we show firms produce more units of the same products. Regressions on the number of products produced at the firm-level yield small and statistically insignificant positive point estimates. ${ }^{28}$ Thus, we conclude that the reform allowed credit constrained firms to produce more of their existing goods, rather than leading the firms to offer new products. The decline in prices combined with the estimated effects on output also implies that the liberalization benefited consumers on two dimensions. Greater quantities were produced and sold at lower prices.

28. These results are available upon request. 


\subsection{Robustness of Firm-level Results}

In this subsection, we provide several robustness tests. These include (i) controlling for differential time trends among industries or by geography, (ii) allowing for different effects by firm size, (iii) controlling for other Indian reforms that may have coincided with financial liberalization, (iv) accounting for differential attrition rates by firms, (v) showing the results are robust to using alternative methods for estimating MRPK and classifying high MRPK firms, and (vi) controlling for cross-industry spillovers.

\section{Differential Time Trends}

Differential time trends pose a threat to our estimation strategy if they are correlated with the deregulation episodes that we study. It is worth emphasizing that the identification assumption for our main misallocation results in Table 3 is already milder than in standard difference-in-differences settings. This is because the key coefficient of interest in equation (4) is $\beta_{2}$, the coefficient on $\operatorname{Reform}_{j t} \times I_{i}^{\text {High } M R P K}$. The estimation of $\beta_{2}$ exploits variation in the within-industry evolution of capital constrained firms' outcomes relative to unconstrained firms. Thus, the key identifying assumption is that, in the absence of the deregulation, the within-industry gap between constrained and unconstrained firms would have evolved in the same way in deregulated and non-deregulated industries, an assumption for which Figure 2 provides graphical evidence.

We next show that our estimates of $\beta_{2}$ are robust to adopting a more conservative specification. We include 5-digit industry-by-year fixed effects in equation (4) to control for any time-varying unobserved characteristics at the most disaggregated industry level possible, including differential time trends. These more stringent fixed effects ensure that the coefficient of $\operatorname{Reform}_{j t} \times I_{i}^{\text {High } M R P K}$ is identified by comparing firms within the same narrowly defined industry in the same year. ${ }^{29}$ In this case, because the reform varies at the 5-digit industry level, the baseline effect of the reform is no longer identified, since it is collinear with the fixed effects, but the differential effect on the high MRPK firms is. Appendix Table A2 reports the results for this specification and shows that the differential effect of the policy on high MRPK firms remains quantitatively similar.

While estimating $\beta_{2}$ tests whether the policy affects misallocation, as we will see in Section 7 , estimating $\beta_{1}$ (the coefficient on Reform $_{j t}$ ) is a necessary step to identify the aggregate effect of the policy. Therefore, the stronger assumption that time trends are parallel between treated and untreated industries is needed to compute the aggregate effects of changing misallocation.

To evaluate whether estimates of $\beta_{1}$ are likely to be affected by differential trends across industries, we include 2-digit industry-by-year fixed effects in equation (4). Including these fixed effects ensures that the average effect of the reform is identified by

29. At the 5-digit level, there are 303 distinct industries in manufacturing. 
comparing firms with similar levels of MRPK across different 5-digit industries that belong to the same 2-digit industry-year. ${ }^{30}$ This strategy effectively accounts for any unobserved time-varying, sector-level shocks, such as aggregate trade shocks and differences in input costs at the 2-digit industry level, as well as sector-level time trends. We report the results in Appendix Table A3. Across all the different firm outcomes, the point estimates are similar to our baseline specification in Table 3 , further suggesting that $\beta_{1}$ is not biased by differential time trends.

\section{Accounting for State-by-Year Fixed Effects}

To account for the possibility that Indian states that are more exposed to the reform due to their industrial composition may have instituted policies affecting misallocation or were affected by shocks concurrent with the reform, we flexibly control for state-level time trends. In the odd columns of Appendix Table A4, we include state-by-year fixed effects in our main specifications. The estimates are therefore identified by comparing firms in the same state and the same year. The inclusion of these controls has little effect on the magnitude of our estimates.

\section{Allowing for Heterogeneous Effects by Firm Size}

If MRPK is correlated with firm size, greater investment in high MRPK firms may be explained by the fact that investors respond to firm size rather than MRPK itself when making investment decisions. ${ }^{31}$ Note that even if investors are basing investment decisions on firm size rather than MRPK, as long as the firms they invest in have ex ante higher MRPK, the policy would still lead to a reduction in misallocation. Nonetheless, it is interesting to know whether the policy's heterogeneous effects on high MRPK firms are driven by heterogeneous effects by firm size. To test whether this is the case, in the even columns of Appendix Table A4, we include controls for pre-reform firm size decile-by-year fixed effects and the log of firm size interacted with Reform f $_{j t}$. Pre-reform firm size is computed using average sales from 1995-2000. Pre-reform firm size decile-by-year fixed effects account for any potential bias due to differential time trends by firm size, while log firm size interacted with Reform f $_{j t}$ controls for the possible mechanism that investors are investing in larger or smaller firms in response to the policy. Our estimates are again quite similar, suggesting that the reduction in misallocation is not due to foreign investors making investments based on firm size.

30. There are 23 distinct 2-digit industries.

31. For example, if larger firms have higher MRPK and foreign investment is more likely to flow to large firms, as suggested by Gopinath, Kalemli-Özcan, Karabarbounis, and Villegas-Sanchez (2017), that could explain our results. 


\section{Controlling for Reservation Laws}

Starting in 1967, the government implemented a policy of reserving certain products for exclusive manufacture by small-scale industry (SSI) firms in order to boost their development. By the end of 1978, more than 800 products had been reserved. In 1996, it was more than a thousand. After the wave of deregulation in the early 1990s, the Indian government decided to remove most of these protective laws, and between 1997 to 2008, the government dereserved almost all products. The consensus is that dereservation led to more entry, higher output, and greater efficiency for deregulated industries. ${ }^{32}$

Because part of the dereservation happened during our sample period, we check that our results are robust to accounting for this deregulation. To do so, we use the list of deregulated industries in ASICC from Boehm, Dhingra, and Morrow (2019) and create a crosswalk between ASICC and our definition of industry (NIC 2008) by using the ASI $2008-2009 .^{33}$

To assess whether dereservation could be driving our results, we perform two tests, both reported in Appendix Table A5. In the odd columns, we exclude all 5-digit NIC industries that contained a product that was affected by a dereservation reform after 2000 (the year before our first episode of liberalization). Because this cuts our sample by more than half, in even columns, we create an indicator variable Dereservation ${ }_{j t}$ that is equal to one after industry $j$ has been dereserved and control for it and its interaction with $I_{i}^{H i g h} M R P K$. In both cases, our main point estimates are virtually unchanged.

\section{Controlling for Trade Liberalization}

India also experienced a massive reduction in its trade tariffs in the 1990s. This raised firms' productivity by increasing competition in the industries in which they operate and allowed them to access a broader set of inputs at a cheaper price (Topalova and Khandelwal, 2011; Goldberg, Khandelwal, Pavcnik, and Topalova, 2010; De Loecker, Goldberg, Khandelwal, and Pavcnik, 2016). If trade liberalization occurred in similar industries to the foreign financial liberalization and its effects took time to appear, this could bias our results.

Our specification with industry-by-year fixed effects already partially accounts for this potential bias, since the trade liberalization occurred at the industry-level. However, it's possible that trade liberalization had a differential effect on capital constrained and unconstrained firms. To account for this, we compute input and output tariffs from 19952010 - the period for which tariff data is available - following Goldberg, Khandelwal,

32. See Garcia-Santana and Pijoan-Mas (2014), Martin, Nataraj, and Harrison (2017), Boehm, Dhingra, and Morrow (2019), and Rotemberg (2019) for a detailed description of the laws and their consequences.

33. We would like to thank the authors for generously sharing their data with us. For each establishment in the ASI, the data reports both the NIC code of the establishment and the list of all the products sold at the ASICC level. We compute a one to one mapping by assigning to each NIC the ASICC with the highest share of products sold. 
Pavcnik, and Topalova (2010) and assume tariffs remain constant for the period 2010$2015 .^{34}$ Input tariff measures are obtained by computing the weighted sum of the percent tariffs on each input used to produce a product based on the Indian input-output table. We then include both the tariff measure and its interaction with $I_{i}^{\text {High } M R P K}$ as controls in our main regression specification.

Appendix Table A6 reports the results when we control for the output tariffs only (the odd columns) or both the output and input tariffs (the even columns). Across the different specifications, the effect of the international capital market liberalization on capital constrained firms remains virtually unchanged.

\section{Firm Entry and Exit}

To examine if our results could be affected by differential attrition between treated and untreated industries, we re-estimate equation (4) using a balanced panel of firms who appear in both 1995 and 2015. Appendix Table A7 reports the results from this exercise. While the balanced samples are substantially smaller for both classifications, the same pattern as before is evident.

Using the industry-level variation in the policy over time, we also directly test whether the policy affected firm exit and entry. If the policy had no effect on attrition, attrition should not bias our results. We identify entry in the data using the year of incorporation and use the last year in the dataset as a proxy for exit. ${ }^{35}$ To estimate the average effect of the policy on exit and entry, we then create counts of the number of firms in a 5 -digit industry-by-year cell that exited or entered. To estimate the differential effect on high and low MRPK firms, we create these counts for industry-year-MPRK category cells.

Appendix Table A8 reports our results. At least in the context of Prowess, we find little evidence that the policy affected entry and exit. ${ }^{36}$ While column 2 does show that the policy had a statistically significant effect on exit for low MRPK firms under the $Y / K$ classification, this effect is small in magnitude (.06 more firms per year) and does not replicate for the LP classification. Altogether, Appendix Table A8 provides further evidence that neither differential attrition nor firm exit and entry themselves are driving the estimated effect of the policy on misallocation.

34. We would like to thank Johanes Boehm for generously sharing his tariff measure with us.

35. True exit is not explicitly recorded in Prowess, since a firm may simply exit the panel because it decides to stop reporting its information to CMIE.

36. This is not necessarily surprising since Prowess only includes large and medium-sized firms, for which exit and entry rates are likely to be relatively low. Indeed, in the average 5-digit industry, there are only 0.84 exit events a year and only 0.033 entry events. In more than $50 \%$ of industry-years, there are zero exits. In $95 \%$ of industry-years, there are zero entrances. 


\section{Alternative Measures of MRPK}

We next test the robustness of the results to two additional methods for estimating MRPK. First, we re-estimate our industry-level production functions as value-added production functions following the methodology of Ackerberg, Caves, and Frazer (2015). Based on these production functions, we recalculate MRPK and re-assign firms to the high MRPK category. Appendix Table A9 reports our results using this alternative classification. Despite a greatly reduced sample size, we again see evidence that the policy increases capital among capital constrained firms and reduces misallocation.

Second, since production function estimation methodologies are designed to estimate quantity production functions, we also take advantage of the fact that Prowess has price and quantity data to use LP to estimate the quantity production functions and then recalculate MRPK. ${ }^{37}$ Appendix Table A10 reports our results using this classification. While the sample size is again significantly smaller than for our main specifications, both qualitatively and quantitatively, the patterns are again very similar.

\section{Spillovers}

Cross-industry spillovers through input-output linkages across treated and non-treated industries could bias our estimates downward if they lead the policy to affect the outcomes of firms in non-liberalized industries.

As in Acemoglu, Akcigit, and Kerr (2016), we separately measure the intensity of the spillover effects of liberalization through the input-output matrix on upstream and downstream industries, using entries of the Leontief inverse matrices as weights:

$$
\text { Upstream }_{k, t}=\sum_{l}\left(\text { Input }_{l \rightarrow k}^{2000}-\mathbf{1}_{l=k}\right) \times \text { Reform }_{l, t}
$$

and

$$
\text { Downstream }_{k, t}=\sum_{l}\left(\text { Output }_{k \rightarrow l}^{2000}-\mathbf{1}_{l=k}\right) \times \text { Reform }_{l, t},
$$

where $k$ and $l$ represents industries at input-output table level, $\mathbf{1}_{l=k}$ is an indicator function for $l=k$, and the summation is over all industries, including industry $k$ itself. The notation Input $\%_{l \rightarrow k}$ represents the elements of the input-output matrix $\mathbf{A}=\left[a_{i j}\right]$, where $a_{i j} \equiv \frac{\text { Sales }_{j \rightarrow i}}{\text { Sales }_{i}}$ measures the total sales of inputs from industry $j$ to industry $i$, as a share of the total inputs of industry $i$. The notation Output $\%_{k \rightarrow l}$ denotes the input-output matrix $\hat{\mathbf{A}}=\left[\hat{a}_{i j}\right]$, where $\hat{a}_{i j} \equiv \frac{\text { Sales }_{i \rightarrow j}}{\text { Sales }_{i}}=a_{j i} \frac{\text { Sales }_{j}}{\text { Sales }_{i}}$ measures the total sales of outputs from industry $i$ to industry $j$, as a share of the total sales of industry $i$. We use the input-output matrices in 2000 since it is the last pre-treatment year and subtract the

37. For multi-product firms, we create a single price by taking the sales-share weighted average of their prices. Then, quantity is given by the firm-level sales divided by this single price. 
direct policy effects by controlling directly for the policy change in industry $k$ in the regression. ${ }^{38}$ We then directly control for these spillover measures in our main regression equations.

Appendix Table A11 reports the results for the average effect of the policy. In Appendix Table A11, we find no evidence of average spillover effects through the production network. Additionally, the positive average effects of the reform are robust to the inclusion of the controls for spillovers. Appendix Table A12 reports the estimates of the heterogeneous effects of the policy, controlling for spillovers. The estimates are again very similar to those that don't account for spillovers.

\section{Extension to Labor Misallocation}

Our results so far show that opening up to foreign capital allowed firms not only to invest more (as seen by the increase in their stock of capital) but also to expand their wage bills. Reducing capital market frictions may simply increase the demand for labor because of the complementarity between capital and labor in the production function. However, it is also possible that the financial liberalization directly reduced labor misallocation, a hypothesis which we test in this section.

Although labor is often modelled as a fully adjustable variable across periods ${ }^{39}$ in reality, labor is likely to have a fixed-cost component due to wage rigidity and hiring/firing costs. As a result, when there is a mismatch between the payments to labor and the generation of cash-flows, financial constraints may affect employment and labor (mis)allocation. Schoefer (2015), Chodorow-Reich (2014), Benmelech, Bergman, and Seru (2015), and Fonseca and Doornik (2019) all provide evidence in support of this channel.

To investigate if the reform reduces labor misallocation, we use the same estimation strategy as before but now compare the effects of the policy on firms with higher or lower marginal revenue products of labor (MRPL) prior to the reform. We classify high and low MRPL firms analogously to how we classify high and low MRPK firms and estimate the heterogeneous effects of the reform on high MRPL firms.

Table 6 reports the results. We find some evidence that following the liberalization, labor constrained firms' revenue differentially increased, although the effect is not statistically significant. These firms also invest $29 \%$ more in physical capital (column 2 , significant at 10\%) relative to low MRPL firms. Interestingly, the largest effect of the reform is on the firm total wage bill (column 3), with a relative increase of $32 \%$. Among ex ante labor constrained firms, MRPL decreased by approximately $35 \%$ (column 4). By

38. We use the input-output matrix for India from the World Input-Output database (Timmer et al., 2015).

39. For example, Olley and Pakes (1996) model labor as a flexible, variable input, while modeling capital as a stock that requires adjustment. 
allowing labor constrained firms to grow faster and to expand employment, the deregulation appears to have led to a reduction in labor misallocation.

\section{$7 \quad$ Aggregate Effects}

Having shown that the liberalization policies reduced misallocation, we now quantify the effect of this reduction on the manufacturing sector's aggregate productivity using equation (2).

\subsection{Identification}

To estimate the different components of equation (2), we split the equation into two parts: a change in firm-level productivity effect and a change in firm-level inputs effect.

Within-Firm Productivity. The contribution of the change in within-firm productivity to the Solow residual is given by $\Delta \log A_{i}$. Since we does not observe a significant effect of the policy on our measures of $\log A_{i}$ in the reduced-form results, we set $\Delta \log A_{i}=0$.

Firm-level Inputs. The contribution of changing firm-level inputs to the Solow residual is given by:

$$
\sum_{\substack{i \in I \\ x \in\{k, l, m\}}} \lambda_{i} \alpha_{i}^{x} \tau_{i}^{x} \Delta \log x_{i}
$$

Most components of this expression are readily observed in the data or given by our natural experiment estimates. $\lambda_{i}$ is the share of firm $i$ 's sales in the total industry sales that is not re-used as manufacturing inputs. ${ }^{40}$ Under the assumption that firms have Cobb-Douglas production functions, $\alpha_{i}^{x}$ is obtained from the LP production function estimates. Finally, $\Delta \log x_{i}$ can be estimated using the coefficients from difference-indifferences regressions with heterogeneous effects where log usage of each input is the outcome variable. Thus, it is straightforward to identify all of the components of the expression capturing the contribution of changing firm-level inputs except $\tau_{i}^{x}$.

Equation (2) highlights that errors in the estimation of $\tau_{i}^{x}$, the level of firm-specific input wedges prior to the policy change, can greatly bias the aggregate policy effects, as $\tau_{i}^{x}$ is multiplicative with $\Delta \log x_{i}$. If we were to use cross-sectional variation in the marginal revenue products of capital, labor, and materials prior to the policy change as measures

40. To be precise, to measure total sales by industry $I$ not re-used by firms in $I$ as inputs, we sum over manufacturing firms' total sales in 2000 (the last pre-treatment year). We then use information from India's input-output table, drawn from the World Input-Output Database (Timmer et al., 2015), to compute the share of output that is re-used by the manufacturing industry as inputs and scale total sales by 1 minus this value. Finally, $\lambda_{i}$ is calculated for a firm $i$ by dividing the firm's sales by this value. 
of $\tau_{i}^{x}$, measurement error would lead to greater dispersion in these values. Since we have shown in Section 5 that the reform has a positive effect on input usages for firms with relatively greater wedges, inflated wedges would be multiplied by the positive estimated change in inputs. Thus, attributing all the dispersion of measured marginal revenue products to wedges would over-estimate the effects of changing input misallocation on aggregate productivity.

We circumvent this challenge by estimating a lower bound measure of equation (8), as described below. In particular, we note that if the policy strictly reduces misallocation that is, inputs do not increase for firms with negative wedges - then the aggregate effects of the policy are strictly increasing in $\tau_{i}^{x}$. Thus, if we can identify lower bound values of $\tau_{i}^{x}$, we can estimate the lower bound effect on the Solow residual.

Identifying the Lower Bound of $\tau_{i}^{x}$. By definition, the post-policy wedge for a firm is always given by: $\tau_{\text {post }}^{x}=\tau_{\text {pre }}^{x}+\Delta \tau^{x}$, where $\Delta \tau^{x}$ is the change in $\tau^{x}$ due to the policy and $i$ is suppressed to simplify notation.

To derive a lower bound, we then make two assumptions. First, we assume the policy does not subsidize treated firms, meaning that wedges do not become negative. In other words, the policy does not increase misallocation. ${ }^{41}$ Second, we assume that the policy had no spillover effects on the wedges and inputs of firms that were not directly treated by the policy. This is the standard difference-in-differences assumption. ${ }^{42}$

Under the assumption that the policy does not subsidize firms, $\tau_{\text {post }}^{x} \geq 0$. Then, $\min _{\tau_{\text {post }}^{x} \geq 0} \tau_{\text {pre }}^{x}=-\Delta \tau^{x}$. Thus, the minimum possible pre-treatment wedge is given by the scenario where, after the policy change, the industry is Pareto-efficient, and there are no wedges left. In this case, any measured dispersion in marginal revenue products after the policy change is attributed to mismeasurement and misspecficiation as opposed to misallocation. So, if we can estimate $\Delta \tau^{x}$, this gives us a lower bound estimate of $\tau_{\text {pre }}^{x}$, and we can apply equation (2) to estimate a lower bound of the first order effects of the policy on the Solow residual.

Since the minimum values of the pre-reform wedges $\tau^{x}$ are given by the change in the wedges due to the policy, and since in our formula, wedges vary at the firm level, we can estimate the minimum wedges with a difference-in-differences regression with heterogeneous effects where the outcome variable is the marginal revenue product of

41. This is consistent with the fact that the average differences in the marginal revenue products of high and low MRPK and MRPL firms at baseline were much higher than the estimated effect of the policy on firms with high MRPK or MRPL.

42. This assumption could be partially relaxed by modeling spillovers explicitly and estimating spillovers effects, as we do in Appendix Table A11. It also allows us to clarify the difference between our aggregation exercise and the exercise in Sraer and Thesmar (2020). Our goal is to estimate the aggregate effect of the existing policy, not to estimate a counterfactual world where the policy would be extended to additional industries, which would relax assumption two. 
input $x$. For example, in the case of $\tau_{i}^{k}$, we estimate

$$
\log M R P K_{i j t}=g_{i}\left(\text { Reform }_{j t}\right)+\mathbf{\Gamma X}_{\mathbf{i t}}+\alpha_{i}+\delta_{t}+\epsilon_{i j t}
$$

where $g_{i}\left(\right.$ Reform $\left._{j t}\right)$ is a flexible function of Reform ${ }_{j t}$, so that the effect of the reform can depend on firms' or industries' attributes. Since we focus on within industry reallocation, allowing the effect of Reform Rt $_{j}$ to depend on firm characteristics is important, as it allows our estimates of $\tau^{k}$ to vary within an industry $j$. As shown in Appendix B, if the policy completely eliminated misallocation, $\hat{g}_{i}(1)$ is an unbiased predictor of $\log \left(1+\tau^{k}\right)$. Then, $\tau^{k}$ can be estimated by computing $\widehat{\tau}_{i}^{k}=e^{\hat{g}_{i}(1)}-1$. The process for estimating $\tau_{i}^{l}$ and $\tau_{i}^{m}$ is exactly the same.

As discussed in Section 4.2, estimating the change in wedges using this differencein-differences specification is less sensitive to the issues that occur when cross-sectional data is used to estimate distortions. To the extent that firms' measurement error is timeinvariant over the period of our experiment, it will be differentiated out by the firm fixed effects $\alpha_{i}$. Time-varying macro-economic shocks or economy-wide changes in markups or the costs of inputs will be absorbed by year fixed effects. Additionally, the effects of timevarying shocks to marginal revenue products, such as productivity shocks, even if they are not economy-wide, will not be attributed to the reform, as long as the standard differencein-differences assumption holds, and they are uncorrelated with Reform ${ }_{j t}$ conditional on the firm and year fixed effects. Thus, the minimum wedges in this context are identified using relatively weak assumptions.

\subsection{Estimation of Wedges and the Change in Inputs}

Since we are interested in how an industry-level policy affected misallocation within an industry, to estimate the aggregate effect of the reform, we need to estimate how the allocation of resources changed across firms within the same industry. In other words, we need to estimate different wedges and changes in inputs for different firms in the same industry. To do so, following our reduced-form strategy, we estimate differencein-differences regressions with heterogeneous effects, allowing the effects of being in a treated industry to depend on firm-level characteristics. ${ }^{43}$ In Appendix C, we discuss how estimation for the aggregation exercise could be implemented in other settings.

In practice, since we observe larger effects on inputs and marginal revenue products for firms with ex ante higher marginal revenue products, we specify $g_{i}$ to allow for heterogeneous effects by firms' pre-treatment marginal revenue products. For the marginal

43. So far, much of the literature has focused on estimating the industry-level effects of policies on the variance of measures of distortions. However, mapping these variances to aggregate productivity growth requires important functional form and distributional assumptions (for example, see Hsieh and Klenow (2009)). Focusing on firm-level effects, combined with the general aggregation formula given by (2), allows for a more non-parametric approach. 
revenue product of capital, we estimate

$$
\begin{aligned}
\log \text { MRPK }_{i j t}= & \beta_{1} \text { Reform }_{j t}+\beta_{2} \text { Reform }_{j t} \times I_{i}^{\text {High MRPK }}+\beta_{3} \text { Reform }_{j t} \times I_{i}^{\text {High MRPM }} \\
& +\beta_{4} \text { Reform }_{j t} \times I_{i}^{\text {High MRPL }}+\mathbf{\Gamma X}_{\mathbf{i t}}+\alpha_{i}+\delta_{t}+\epsilon_{i j t}
\end{aligned}
$$

Then

$$
\begin{aligned}
\widehat{\log \left(1+\tau_{i}^{k}\right)}= & \hat{\beta}_{1} \text { Reform }_{j}+\hat{\beta}_{2} \text { Reform }_{j} \times I_{i}^{\text {High MRPK }}+\hat{\beta}_{3} \text { Reform }_{j} \times I_{i}^{\text {High MRPM }} \\
& +\hat{\beta}_{4} \text { Reform }_{j} \times I_{i}^{\text {High MRPL }}
\end{aligned}
$$

where Reform $_{j}$ is again an indicator variable equal to 1 if a firm is in an industry that liberalized between 1995 and 2015 .

Our regression specifications for MRPL, MRPM, capital, labor, and materials are analogous, and the results are reported in Appendix Table A13.

\subsection{Results}

Lower Bound Estimate. Now that we have estimated all the components of equation (2), we can calculate the lower bound effect of the policy on the Solow residual. We estimate that the policy increased the Solow residual by at least $6.5 \%$ (see row 1 of Table 7). ${ }^{44}$ To evaluate the magnitude of this effect, we can compare it to estimates of the gains from reallocation in Indian manufacturing from Nishida, Petrin, Rotemberg, and White (2017). Nishida, Petrin, Rotemberg, and White (2017) estimate the yearly increase in aggregate productivity in Indian manufacturing due to reallocation from 2000-2010. From 2006 (the earliest year following both liberalizations) to 2010, there are gains of approximately $35 \%$. Thus, our estimated lower bound effect accounts for roughly $20 \%$ of the increase in manufacturing productivity over this period.

Comparison with Alternative Estimates. We next compare this lower bound estimate to estimates of the aggregate effect using alternative measures of the baseline wedges. It is common in the misallocation literature to estimate levels of distortions by using cross-sectional dispersion in marginal revenue products. This approach has recently been criticized by Haltiwanger, Kulick, and Syverson (2018), Rotemberg and White (2017), and Asker, Collard-Wexler, and De Loecker (2014) for inflating the effects of misallocation. For comparison to our lower bound approach, we use equation (2) to estimate the effects of the policies on the Solow residual if we computed the baseline wedges by attributing all of the dispersion in MRPK, MRPL, and MRPM to misallocation. If we attribute all the dispersion within a 5-digit manufacturing industry to misallocation,

44. Using the values for $\alpha^{x}$ from the quantity production function estimation instead of the revenue production function estimation delivers a similar estimate, $5.5 \%$. 
we estimate that the policy would increase the Solow residual by $159 \%$ (Table 7 , row 2). However, this large effect is driven by outliers. If we additionally winsorize the top and bottom $15 \%$ of deviations, we find that the policy increased the Solow residual by $10.2 \%$ (Table 7, row 3). The fact that winsorizing has a meaningful effect on the estimates is consistent with the findings of Rotemberg and White (2017), who show that winsorizing has large effects on the degree of measured misallocation in cross-sectional data from the U.S. and India. Given the range of estimates produced by different choices about the treatment of outliers, it appears that approaches that use cross-sectional variation to identify wedges will be highly sensitive to arbitrary choices of where to winsorize or trim data.

\section{Conclusion}

This paper addresses two key challenges in a growing literature on misallocation. First, we develop new tools for measuring the aggregate effects of policies that reduce misallocation, which do not rely on observed cross-sectional variation in the marginal revenue products of inputs. Second, we provide evidence on an important lever that policy-makers can use to reduce misallocation, particularly in low-income countries, where the costs of misallocation are likely to be great.

Exploiting within-country, within-industry and cross-time variation, we show that foreign capital liberalization reduced the misallocation of capital and labor in India. The liberalization, which allowed for the automatic approval of foreign investments and raised caps on foreign equity in the 2000's, increased capital in the treated industries. However, the effects of the liberalization on the average firm mask important heterogeneity in the policy effect. The entirety of the liberalization's effect on firms' outcomes is driven by increased investment in firms that previously had high marginal revenue products of capital/high sales to capital ratios. Thus, the policy change reduced the marginal revenue returns to capital for these firms, reducing misallocation. These results suggest that foreign capital liberalization may be an important tool for low-income countries to reduce capital market frictions.

Aggregating our reduced-form estimates, we also find that the policy increased the manufacturing's industry's Solow residual by at least $6.5 \%$. In contrast, if we assumed all the dispersion in the marginal revenue products of inputs was due to misallocation, we would estimate the policy increased the Solow residual by $159 \%$. Our methodology, which is less sensitive to measurement error or outliers, can be applied to other settings where there is an exogeneous shock to firms' input wedges. Thus, our results provide evidence that quasi-experimental variation can improve the measurement of the aggregate effects of reducing misallocation. 


\section{References}

Acemoglu, Daron, Ufuk Akcigit, and William Kerr. 2016. "Networks and the macroeconomy: An empirical exploration." NBER Macroeconomics Annual 30 (1): 273-335.

Ackerberg, Daniel A, Kevin Caves, and Garth Frazer. 2015. "Identification properties of recent production function estimators." Econometrica 83 (6): 2411-2451.

Aghion, Philippe, Robin Burgess, Stephen J Redding, and Fabrizio Zilibotti. 2008. "The unequal effects of liberalization: Evidence from dismantling the License Raj in India." American Economic Review 98 (4): 1397-1412.

Alfaro, Laura, Areendam Chanda, Sebnem Kalemli-Ozcan, and Selin Sayek. 2004. "FDI and economic growth: the role of local financial markets." Journal of International Economics 64 (1): 89-112.

Alfaro, Laura, and Anusha Chari. 2015. "Deregulation, Misallocation, and Size: Evidence from India." Journal of Law and Economics 57 (4): 897-936.

Allcott, Hunt, Allan Collard-Wexler, and Stephen D O Connell. 2016. "How Do Electricity Shortages Affect Industry? Evidence From India." American Economic Review 106 (3): $587-624$.

Amirapu, Amrit, and Michael Gechter. 2019. "Labor Regulations and the Cost of Corruption: Evidence from the Indian Firm Size Distribution." Review of Economics and Statistics: $1-48$.

Asker, John, Allan Collard-Wexler, and Jan De Loecker. 2014. "Dynamic Inputs and Resource (Mis)Allocation." Journal of Political Economy 122 (5): 1013-1063.

Bai, John, Daniel Carvalho, and Gordon M. Phillips. 2018. "The Impact of Bank Credit on Labor Reallocation and Aggregate Industry Productivity" [in English]. Journal of Finance 73 (6): 2787-2836.

Banerjee, A. V., and K. Munshi. 2004. "How Efficiently is Capital Allocated? Evidence from the Knitted Garment Industry in Tipur." Review of Economic Studies 71 (1): $19-42$.

Banerjee, Abhijit V., Esther Duflo, Rachel Glennerster, and Cynthia Kinnan. 2015. "The Miracle of Microfinance? Evidence from a Randomized Evaluation." American Economic Journal: Applied Economics 7 (1): 22-53.

Banerjee, Abhijit V, and Esther Duflo. 2014. "Do Firms Want to Borrow More? Testing Credit Constraints Using a Directed Lending Program." Review of Economic Studies 81 (2): 572-607. 
Banerjee, Abhijit V, Esther Duflo, and Kaivan Munshi. 2003. "The (Mis)allocation of Capital." Journal of the European Economic Association 1 (2-3): 484-494.

Banerjee, Abhijit V, and Benjamin Moll. 2010. "Why Does Misallocation Persist?" American Economic Journal: Macroeconomics 2 (1): 189-206.

Baqaee, David, and Emmanuel Farhi. forthcoming. "Productivity and Misallocation in General Equilibrium," Quarterly Journal of Economics.

— 2019. "A Short Note on Aggregating Productivity," NBER Working Paper, no. 25688 .

Bartelsman, Eric, John Haltiwanger, and Stefano Scarpetta. 2013. "Cross-Country Differences in Productivity: The Role of Allocation and Selection." American Economic Review 103 (1): 305-334.

Benmelech, Efraim, Nittai K Bergman, and Amit Seru. 2015. "Financing Labor." NBER Working Paper, Working Paper Series, no. 17144.

Bento, Pedro, and Diego Restuccia. 2017. "Misallocation, Establishment Size, and Productivity." American Economic Journal: Macroeconomics 9 (3): 267-303.

Bils, Mark, Peter Klenow, and Cian Ruane. 2018. "Misallocation or Mismeasurement?," Working paper.

Bloom, Nicholas, Benn Eifert, Aprajit Mahajan, David McKenzie, and John Roberts. 2013. "Does Management Matter? Evidence from India." Quarterly Journal of Economics 128 (1): 1-51.

Boehm, Johannes, Swati Dhingra, and John Morrow. 2019. "The Comparative Advantage of Firms." Working Paper.

Boehm, Johannes, and Ezra Oberfield. 2018. "Misallocation in the Market for Inputs : Enforcement and the Organization of Production," NBER Working Paper, no. 24937.

Bollard, Albert, Peter J Klenow, and Gunjan Sharma. 2013. "Indias mysterious manufacturing miracle." Review of Economic Dynamics 16 (1): 59-85.

Buera, Francisco J, Joseph P Kaboski, and Yongseok Shin. 2011. "Finance and Development: A Tale of Two Sectors." American Economic Review 101 (5): 1964-2002.

Burgess, Robin, and Rohini Pande. 2005. "Do rural banks matter? Evidence from the Indian social banking experiment." American Economic Review 95 (3): 780-795. 
Catherine, Sylvain, Thomas Chaney, Zongbo Huang, David Alexandre Sraer, and David Thesmar. 2018. "Quantifying Reduced-Form Evidence on Collateral Constraints," Working paper.

Chari, A V. 2011. "Identifying the Aggregate Productivity Effects of Entry and Size Restrictions: An Empirical Analysis of License Reform in lndia." American Economic Journal: Economic Policy 3 (2): 66-96.

Chari, Anusha, and Nandini Gupta. 2008. "Incumbents and protectionism: The political economy of foreign entry liberalization." Darden - JFE Conference Volume: Capital Raising in Emerging Economies, Journal of Financial Economics 88 (3): 633-656.

Chodorow-Reich, Gabriel. 2014. "The Employment Effects of Credit Market Disruptions: Firm-level Evidence from the 2008-9 Financial Crisis." Quarterly Journal of Economics 129 (1): 1-59.

Cole, Shawn. 2009. "Financial Development, Bank Ownership, and Growth: or, Does Quantity Imply Quality?" Review of Economics and Statistics 91 (1): 33-51.

Collard-Wexler, Allan, John Asker, and Jan De Loecker. 2011. "Productivity Volatility and the Misallocation of Resources in Developing Economies," NBER Working Paper, no. 17175 .

David, Joel M, Hugo A Hopenhayn, and Venky Venkateswaran. 2016. "Information, Misallocation and Aggregate Productivity." Quarterly Journal of Economics.

David, Joel M, and Venky Venkateswaran. 2019. "The Sources of Capital Misallocation." American Economic Review 109 (7): 2531-2567.

De Loecker, Jan, Pinelopi K Goldberg, Amit K Khandelwal, and Nina Pavcnik. 2016. "Prices, Markups, and Trade Reform." Econometrica 84 (2): 445-510.

Detragiache, E, T Tressel, and P Gupta. 2008. "Foreign banks in poor countries: theory and evidence." Journal of Finance 63 (5): 2123-2160.

Dinc, I Serdar, and Nandini Gupta. 2011. "The Decision to Privatize: Finance and Politics." Journal of Finance 66 (1): 241-269.

Duranton, D., E. Ghani, A. Goswani, and W. Kerr. 2017. "Misallocation in India," Working paper.

Fonseca, Julia, and Bernardus Van Doornik. 2019. "Financial Development, Labor Markets, and Aggregate Productivity: Evidence from Brazil," Working paper. 
Foster, Lucia, John Haltiwanger, and Chad Syverson. 2008. "Reallocation, Firm Turnover, and Efficiency: Selection on Productivity or Profitability?" American Economic Review 98 (1): 394-425.

Garcia-Santana, Manuel, and Josep Pijoan-Mas. 2014. "The reservation laws in India and the misallocation of production factors." Journal of Monetary Economics 66:193209.

Ghani, Ejaz, Arti Grover Goswami, and William R Kerr. 2016. "Highway to success: The impact of the Golden Quadrilateral project for the location and performance of Indian manufacturing." Economic Journal 126 (591): 317-357.

Goldberg, Pinelopi Koujianou, Amit Kumar Khandelwal, Nina Pavcnik, and Petia Topalova. 2010. "Imported Intermediate Inputs and Domestic Product Growth: Evidence from India." Quarterly Journal of Economics 125 (4): 1727-1767.

Gollin, Douglas, and Christopher R Udry. 2019. "Heterogeneity, Measurement Error and Misallocation: Evidence from African Agriculture," NBER Working Paper, no. 25440 .

Gopinath, Gita, Şebnem Kalemli-Özcan, Loukas Karabarbounis, and Carolina VillegasSanchez. 2017. "Capital allocation and productivity in South Europe." Quarterly Journal of Economics 132 (4): 1915-1967.

Gormley, Todd A. 2010. "The impact of foreign bank entry in emerging markets: Evidence from India." Journal of Financial Intermediation 19 (1): 26-51.

Guner, Nezih, Gustavo Ventura, and Yi Xu. 2008. "Macroeconomic implications of sizedependent policies." Review of Economic Dynamics 11 (4): 721-744.

Gupta, Nandini. 2005. "Partial Privatization and Firm Performance." Journal of Finance 60 (2): 987-1015.

Haltiwanger, John, Robert Kulick, and Chad Syverson. 2018. "Misallocation Measures: The Distortion That Ate the Residual," NBER Working Paper, no. 24199.

Hsieh, Chang-Tai, and Peter J Klenow. 2009. "Misallocation and manufacturing TFP in China and India." Quarterly Journal of Economics 124 (4): 1403-1448.

Kalemli-Ozcan, Sebnem, and Bent E Sørensen. 2014. "Misallocation, Property Rights, and Access to Finance: Evidence from within and across Africa." In African Successes, Volume III: Modernization and Development, 183-211. University of Chicago Press. 
Krueger, Anne O, et al. 2002. Economic policy reforms and the Indian economy. University of Chicago Press.

Larrain, Mauricio, and Sebastian Stumpner. 2017. "Capital account liberalization and aggregate productivity: The role of firm capital allocation." Journal of Finance 72 (4): $1825-1858$.

Levinsohn, James, and Amil Petrin. 2003. "Estimating production functions using inputs to control for unobservables." Review of Economic Studies 70 (2): 317-341.

Martin, Leslie A., Shanthi Nataraj, and Ann E. Harrison. 2017. "In with the big, out with the small: Removing small- scale reservations in India." American Economic Review 107 (2): 354-386.

Mian, Atif. 2006. "Distance constraints: The limits of foreign lending in poor economies." Journal of Finance 61 (3): 1465-1505.

Midrigan, Virgiliu, and Daniel Yi Xu. 2014. "Finance and Misallocation: Evidence from Plant-Level Data." American Economic Review 104 (2): 422-458.

Moll, Benjamin. 2014. "Productivity Losses from Financial Frictions: Can Self-Financing Undo Capital Misallocation?" American Economic Review 104 (10): 3186-3221.

Nishida, Mitsukuni, Amil Petrin, Martin Rotemberg, and T. Kirk White. 2017. "Are We Undercounting Reallocation's Contribution to Growth?" Working Paper.

Oberfield, Ezra. 2013. "Productivity and misallocation during a crisis: Evidence from the Chilean crisis of 1982." Review of Economic Dynamics 16 (1): 100-119.

Olley, G Steven, and Ariel Pakes. 1996. "The Dynamics of Productivity in the Telecommunications Equipment Industry." Econometrica: 1263-1297.

Panagariya, Arvind. 2008. India: The emerging giant. Oxford University Press.

Petrin, Amil, and James Levinsohn. 2012. "Measuring aggregate productivity growth using plant-level data." The RAND Journal of Economics 43 (4): 705-725.

Restuccia, Diego, and Richard Rogerson. 2008. "Policy distortions and aggregate productivity with heterogeneous establishments." Review of Economic Dynamics 11 (4): 707-720.

. 2013. "Misallocation and productivity." Review of Economic Dynamics 1 (16): $1-10$.

2017. "The Causes and Costs of Misallocation." Journal of Economic Perspectives 31 (3): 151-174. 
Rotemberg, Martin. 2019. "Equilibrium effects of firm subsidies." American Economic Review 109 (10): 3475-3513.

Rotemberg, Martin, and Kirk White. 2017. "Measuring Cross-Country Differences in Misallocation," Working paper.

Saffie, Felipe, Liliana Varela, and Kei-Mu Yi. 2018. "Firm-Level Structural Change: Supply and Demand Effects of Financial Liberalization," Working paper.

Schoefer, Benjamin. 2015. "The financial channel of wage rigidity," Working paper.

Sivadasan, Jagadeesh. 2009. "Barriers to competition and productivity: Evidence from India." BE Journal of Economic Analysis \& Policy 9 (1).

Sraer, David Alexandre, and David Thesmar. 2020. "A Sufficient Statistics Approach for Aggregating Firm-Level Experiments." NBER Working Paper.

Syverson, Chad. 2011. "What Determines Productivity?" Journal of Economic Literature 49 (2): $326-365$.

Timmer, Marcel P, Erik Dietzenbacher, Bart Los, Robert Stehrer, and Gaaitzen J De Vries. 2015. "An illustrated user guide to the world input-output database: The case of global automotive production." Review of International Economics 23 (3): 575605.

Topalova, Petia. 2007. "Trade liberalization, poverty and inequality: Evidence from Indian districts." In Globalization and poverty, 291-336. University of Chicago Press.

2010. "Factor immobility and regional impacts of trade liberalization: Evidence on poverty from India." American Economic Journal: Applied Economics 2 (4): 141.

Topalova, Petia, and Amit Khandelwal. 2011. "Trade Liberalization and Firm Productivity: The Case of India." Review of Economics and Statistics 93 (3): 995-1009.

Townsend, Robert. 1994. "Risk and Insurance in Village India." Econometrica 62:539591.

Udry, Christopher. 1994. "Risk and Insurance in a Rural Credit Market: An Empirical Investigation in Northern Nigeria." Review of Economic Studies 61 (3): 495-526.

Varela, Liliana. 2017. "Reallocation, Competition, and Productivity: Evidence from a Financial Liberalization Episode." Review of Economic Studies 85 (2): 1279-1313.

Vig, Vikrant. 2013. "Access to Collateral and Corporate Debt Structure: Evidence from a Natural Experiment." Journal of Finance 68 (3): 881-928. 
Wooldridge, Jeffrey M. 2009. "On estimating firm-level production functions using proxy variables to control for unobservables." Economics Letters 104 (3): 112-114. 


\section{Figures}

Figure 1: Distribution of $\log (\mathrm{MRPK})$ in 2000

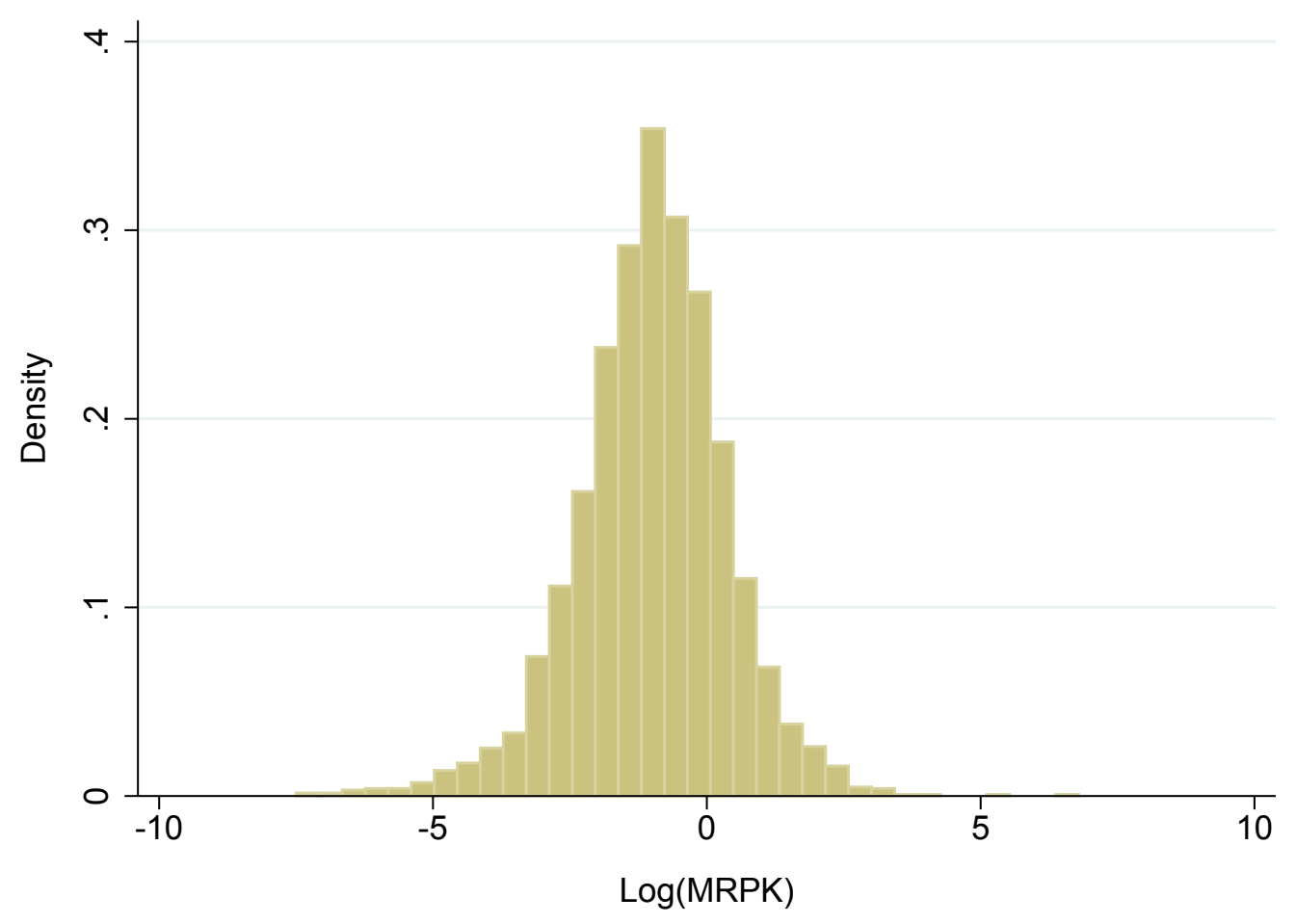

This figure displays the distribution of $\log (\mathrm{MRPK})$ for manufacturing firms in the Prowess data in 2000, the year before the first deregulation episode in 2001. MRPK is computed from revenue production functions estimated with the methodology of Levinsohn and Petrin (2003). 
Figure 2: Event Study Graphs for the Relative Effect of Foreign Capital Liberalization on High MRPK Firms
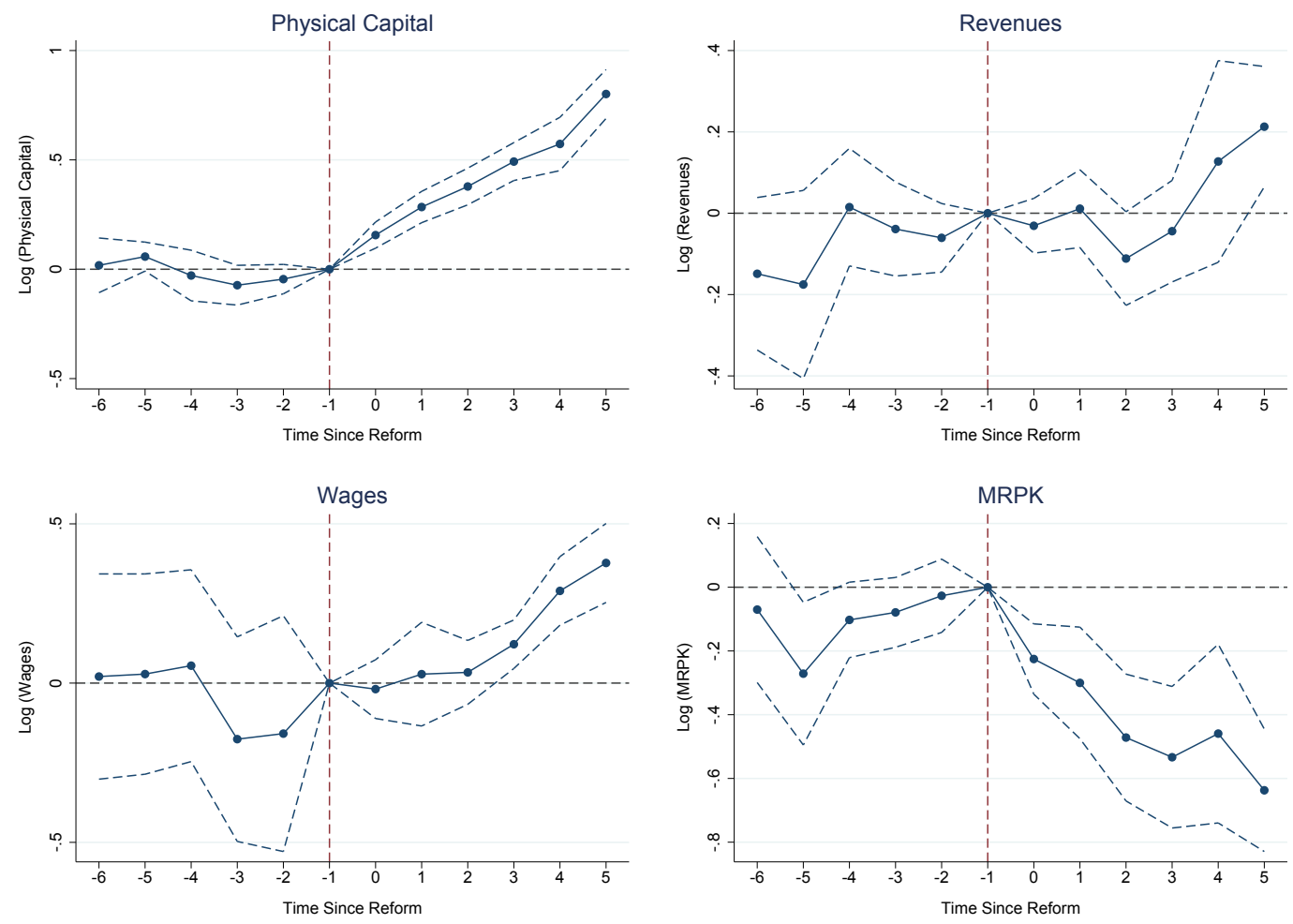

This figure reports event study graphs for the relative effects of the liberalization on firms with high pre-treatment MRPK relative to those with low pre-treatment MRPK in treated industries. All dependent variables are in logs. MRPK is calculated using $Y / K$ as a within-4 digit industry proxy for MRPK. 


\section{Tables}

Table 1: Summary Statistics for Manufacturing Firms in the Prowess Data

\begin{tabular}{lccccc}
\hline & & & & & \\
& Obs. & Mean & p10 & p50 & p90 \\
\hline Treated During Study Period (\%) & 66,654 & 9 & 0 & 0 & 0 \\
Private, Domestic (\%) & 66,654 & 57 & 0 & 100 & 100 \\
Private, Foreign (\%) & 66,654 & 5 & 0 & 0 & 0 \\
State Owned (\%) & 66,654 & 4 & 0 & 0 & 0 \\
Firm Age & 66,654 & 26 & 8 & 21 & 52 \\
Gross Fixed Assets (Deflated) & 63,950 & 23 & 0 & 3 & 37 \\
Sales/Revenues (Deflated) & 62,784 & 58 & 1 & 11 & 107 \\
Salaries (Deflated) & 49,090 & 3 & 0 & 1 & 6 \\
Income & 64,155 & 68 & 1 & 10 & 115 \\
\hline
\end{tabular}

This table reports summary statistics for the manufacturing firms appearing in the CMIE Prowess dataset from 1995 to 2015. An observation is at the firm-year level. Firms' capital, income, salaries, and revenues are measured in millions of USD. The 10th, 50th, and 90th percentiles are given by p10, p50, and p90, respectively. 
Table 2: Average Effect of the Foreign Capital Liberalization

\begin{tabular}{|c|c|c|c|c|c|}
\hline \multirow[t]{2}{*}{ Dependent Variable } & Revenues & Capital & Wages & MRPK & TFPR \\
\hline & (1) & $(2)$ & $(3)$ & (4) & (5) \\
\hline Reform $_{j t}$ & $\begin{array}{c}0.22^{* * *} \\
(0.07)\end{array}$ & $\begin{array}{c}0.29 * * * \\
(0.10)\end{array}$ & $\begin{array}{c}0.14 \\
(0.11)\end{array}$ & $\begin{array}{c}-0.18 \\
(0.11)\end{array}$ & $\begin{array}{c}-0.08 \\
(0.06)\end{array}$ \\
\hline Observations & 62,636 & 63,704 & 48,983 & 61,081 & 44,888 \\
\hline Firm FE & $\checkmark$ & $\checkmark$ & $\checkmark$ & $\checkmark$ & $\checkmark$ \\
\hline Year FE & $\checkmark$ & $\checkmark$ & $\checkmark$ & $\checkmark$ & $\checkmark$ \\
\hline Age FE & $\checkmark$ & $\checkmark$ & $\checkmark$ & $\checkmark$ & $\checkmark$ \\
\hline
\end{tabular}

This table reports difference-in-differences estimates of the effect of the foreign capital liberalization (equation (6)) over the period 1995-2015. All dependent variables are in logs. Reform ${ }_{j t}$ is an indicator variable equal to one if the industry had liberalized access to the international capital market in or before year $t$ and zero otherwise. In column 4 , MPRK is computed using $Y / K$ as a proxy for the marginal revenue product of capital. In column 5, TFPR is computed by estimating the production function using the method of Levinsohn and Petrin (2003). Standard errors are twoway clustered at the 4-digit industry and year level. *, **, and ${ }^{* * *}$ denote 10,5 , and $1 \%$ statistical significance respectively. 
Table 3: Effect of Foreign Capital Liberalization by Firms' Ex Ante Capital Constraints

\begin{tabular}{|c|c|c|c|c|c|}
\hline \multirow[t]{2}{*}{ Dependent Variable } & Revenues & Capital & Wages & MRPK & TFPR \\
\hline & (1) & $(2)$ & $(3)$ & $(4)$ & (5) \\
\hline & \multicolumn{5}{|c|}{ Panel A: Y/K Classification } \\
\hline Reform $_{j t} \times I_{i}^{H i g h M R P K}$ & $\begin{array}{c}0.18^{* * *} \\
(0.05)\end{array}$ & $\begin{array}{c}0.60^{* * *} \\
(0.07)\end{array}$ & $\begin{array}{c}0.26^{* *} \\
(0.11)\end{array}$ & $\begin{array}{c}-0.43^{* * *} \\
(0.08)\end{array}$ & $\begin{array}{l}-0.07 \\
(0.06)\end{array}$ \\
\hline Reform $_{j t}$ & $\begin{array}{c}0.12 \\
(0.08)\end{array}$ & $\begin{array}{l}-0.04 \\
(0.09)\end{array}$ & $\begin{array}{l}-0.01 \\
(0.09)\end{array}$ & $\begin{array}{c}0.07 \\
(0.12)\end{array}$ & $\begin{array}{l}-0.04 \\
(0.08)\end{array}$ \\
\hline Observations & 62,636 & 63,704 & 48,983 & 61,081 & 44,888 \\
\hline Firm FE & $\checkmark$ & $\checkmark$ & $\checkmark$ & $\checkmark$ & $\checkmark$ \\
\hline Year FE & $\checkmark$ & $\checkmark$ & $\checkmark$ & $\checkmark$ & $\checkmark$ \\
\hline Age FE & $\checkmark$ & $\checkmark$ & $\checkmark$ & $\checkmark$ & $\checkmark$ \\
\hline
\end{tabular}

Panel B: LP Classification

\begin{tabular}{lccccc} 
Reform $_{j t} \times I_{i}^{\text {High MRPK }}$ & $\begin{array}{c}0.23^{* *} \\
(0.09)\end{array}$ & $\begin{array}{c}0.46^{* * *} \\
(0.15)\end{array}$ & $\begin{array}{c}0.31^{* *} \\
(0.11)\end{array}$ & $\begin{array}{c}-0.56^{* * *} \\
(0.11)\end{array}$ & $\begin{array}{c}-0.13 \\
(0.08)\end{array}$ \\
Reform $_{j t}$ & 0.12 & 0.08 & -0.01 & 0.19 & -0.00 \\
& $(0.08)$ & $(0.07)$ & $(0.09)$ & $(0.12)$ & $(0.09)$ \\
\hline Observations & 50,070 & 50,478 & 41,035 & 38,613 & 38,613 \\
Firm FE & $\checkmark$ & $\checkmark$ & $\checkmark$ & $\checkmark$ & $\checkmark$ \\
Year FE & $\checkmark$ & $\checkmark$ & $\checkmark$ & $\checkmark$ & $\checkmark$ \\
Age FE & $\checkmark$ & $\checkmark$ & $\checkmark$ & $\checkmark$ & $\checkmark$ \\
\hline
\end{tabular}

This table reports estimates of the effect of foreign capital liberalization on high and low pre-treatment MRPK firms (equation (4)) over the period 1995-2015. All dependent variables are in logs. Firms are classified as high MRPK if their average MRPK in the pre-treatment period from 1995-2000 is above the 4-digit industry median. In Panel A, MRPK is estimated with the $Y / K$ method. In Panel B, it is estimated by estimating the production function using the methodology of Levinsohn and Petrin (2003). Standard errors are twoway clustered at the 4-digit industry and year level. *, **, and *** denote $10 \%$, $5 \%$, and $1 \%$ statistical significance respectively. 
Table 4: Heterogenous Effect of Foreign Capital Liberalization: Local Financial Development

\begin{tabular}{|c|c|c|c|c|}
\hline \multirow[t]{2}{*}{ Dependent Variable } & Revenues & Capital & Wages & MRPK \\
\hline & (1) & $(2)$ & $(3)$ & $(4)$ \\
\hline & \multicolumn{4}{|c|}{ Panel A: Y/K Classification } \\
\hline Reform $_{j t} \times I_{i}^{\text {High MRPK }}$ & $\begin{array}{c}0.17^{* * *} \\
(0.00)\end{array}$ & $\begin{array}{c}0.60^{* * *} \\
(0.00)\end{array}$ & $\begin{array}{l}0.26^{* *} \\
(0.03)\end{array}$ & $\begin{array}{c}-0.44^{* * *} \\
(0.00)\end{array}$ \\
\hline $\begin{array}{l}\text { Reform }_{j t} \times I_{i}^{\text {High MRPK }} \\
\quad \times \text { Local Credit Market Development }\end{array}$ & $\begin{array}{c}-0.15^{* *} \\
(0.02)\end{array}$ & $\begin{array}{c}-0.27^{* * *} \\
(0.00)\end{array}$ & $\begin{array}{c}-0.16^{* * *} \\
(0.00)\end{array}$ & $\begin{array}{l}0.08^{*} \\
(0.05)\end{array}$ \\
\hline Observations & 57,636 & 58,733 & 45,161 & 56,183 \\
\hline Double and Single Interactions & $\checkmark$ & $\checkmark$ & $\checkmark$ & $\checkmark$ \\
\hline Firm FE & $\checkmark$ & $\checkmark$ & $\checkmark$ & $\checkmark$ \\
\hline Year FE & $\checkmark$ & $\checkmark$ & $\checkmark$ & $\checkmark$ \\
\hline Age FE & $\checkmark$ & $\checkmark$ & $\checkmark$ & $\checkmark$ \\
\hline
\end{tabular}

Panel B: LP Classification

\begin{tabular}{lcccc} 
Reform $_{j t} \times I_{i}^{\text {High MRPK }}$ & $0.23^{* *}$ & $0.46^{* *}$ & $0.32^{* *}$ & $-0.52^{* * *}$ \\
& $(0.01)$ & $(0.02)$ & $(0.02)$ & $(0.00)$ \\
Reform $_{j t} \times I_{i}^{\text {High MRPK }}$ & -0.15 & $-0.33^{* * *}$ & $-0.19^{* *}$ & $0.12^{*}$ \\
$\times$ Local Credit Market Development & $(0.10)$ & $(0.00)$ & $(0.01)$ & $(0.06)$ \\
\hline Observations & 57,636 & 58,733 & 45,161 & 56,183 \\
Double and Single Interactions & $\checkmark$ & $\checkmark$ & $\checkmark$ & $\checkmark$ \\
Firm FE & $\checkmark$ & $\checkmark$ & $\checkmark$ & $\checkmark$ \\
Year FE & $\checkmark$ & $\checkmark$ & $\checkmark$ & $\checkmark$ \\
Age FE & $\checkmark$ & $\checkmark$ & $\checkmark$ & $\checkmark$ \\
\hline
\end{tabular}

This table reports estimates of the effect of the foreign capital liberalization on high and low pre-treatment MRPK firms by ex ante state-level financial development. All dependent variables are in logs. Re form ${ }_{j t}$ is an indicator variable equal to one if the industry has liberalized access to the international capital market. Firms are classified as high MRPK if their average MRPK in the pre-treatment period from 1995-2000 is above the 4-digit industry median. In Panel A, MRPK is calculated using the Y/K method. In Panel $\mathrm{B}$, it is calculated by estimating the production function using the methodology of Levinsohn and Petrin (2003). Local credit market development is proxied using the amount of bank credit in the state in the pre-treatment period. Double and single interactions consist of the relevant controls for the triple-differences specification. Standard errors are twoway clustered at the 4-digit industry and year level. ${ }^{*}, * *$, and $* * *$ denote $10 \%, 5 \%$, and $1 \%$ statistical significance respectively. 
Table 5: Effect of Foreign Capital Liberalization on Prices and Product Output

\begin{tabular}{|c|c|c|c|c|c|c|}
\hline \multirow[t]{2}{*}{ Dependent Variable } & \multicolumn{3}{|c|}{ Log Unit Price } & \multicolumn{3}{|c|}{ Log Output } \\
\hline & (1) & (2) & (3) & (4) & (5) & (6) \\
\hline Reform $_{j t}$ & $\begin{array}{l}-0.09^{*} \\
(0.05)\end{array}$ & $\begin{array}{l}-0.03 \\
(0.04)\end{array}$ & $\begin{array}{l}-0.06 \\
(0.04)\end{array}$ & $\begin{array}{c}0.23^{* * *} \\
(0.08)\end{array}$ & $\begin{array}{c}0.14^{* *} \\
(0.06)\end{array}$ & $\begin{array}{c}0.07 \\
(0.07)\end{array}$ \\
\hline $\operatorname{Reform}_{j t} \times I_{i}^{\text {High MRPK }}(Y / K)$ & & $\begin{array}{c}-0.09^{* *} \\
(0.04)\end{array}$ & & & $\begin{array}{l}0.13^{*} \\
(0.08)\end{array}$ & \\
\hline $\operatorname{Reform}_{j t} \times I_{i}^{\text {High MRPK }}(L P)$ & & & $\begin{array}{c}-0.03^{* * *} \\
(0.00)\end{array}$ & & & $\begin{array}{l}0.27^{*} \\
(0.16)\end{array}$ \\
\hline Observations & 149,867 & 149,867 & 124,212 & 151,113 & 151,113 & 125,244 \\
\hline Firm-Product FE & $\checkmark$ & $\checkmark$ & $\checkmark$ & $\checkmark$ & $\checkmark$ & $\checkmark$ \\
\hline Year FE & $\checkmark$ & $\checkmark$ & $\checkmark$ & $\checkmark$ & $\checkmark$ & $\checkmark$ \\
\hline Age FE & $\checkmark$ & $\checkmark$ & $\checkmark$ & $\checkmark$ & $\checkmark$ & $\checkmark$ \\
\hline
\end{tabular}

This table reports estimates of the effect of foreign capital liberalization on unit prices and product output (equations (7)) for the period 1995-2015. Each observation is at the firm-product-year level. Firms are classified as high MRPK if their average MRPK in the pre-treatment period from 1995-2000 is above the 4-digit industry median. In columns 2 and 5, MRPK is calculated as $Y / K$. In columns 3 and 6 , it is calculated by estimating the production function using Levinsohn and Petrin (2003) methods. Standard errors are twoway clustered at the 4-digit industry and year level. *, **, and *** denote $10 \%$, $5 \%$, and $1 \%$ statistical significance respectively 
Table 6: Effect of Foreign Capital Liberalization by Firms' Ex Ante MRPL

\begin{tabular}{|c|c|c|c|c|}
\hline \multirow[t]{2}{*}{ Dependent Variable } & Revenues & Capital & Wages & MRPL \\
\hline & (1) & $(2)$ & $(3)$ & $(4)$ \\
\hline & \multicolumn{4}{|c|}{$\underline{\text { Panel A: Y/L Classification }}$} \\
\hline Reform $_{j t} \times I_{i}^{H i g h M R P L}$ & $\begin{array}{c}0.15 \\
(0.11)\end{array}$ & $\begin{array}{l}0.29^{*} \\
(0.15)\end{array}$ & $\begin{array}{c}0.32^{* * *} \\
(0.08)\end{array}$ & $\begin{array}{c}-0.35^{* * *} \\
(0.09)\end{array}$ \\
\hline Reform $_{j t}$ & $\begin{array}{c}0.17^{* * *} \\
(0.05)\end{array}$ & $\begin{array}{c}0.19^{* * *} \\
(0.05)\end{array}$ & $\begin{array}{c}-0.00 \\
(0.10)\end{array}$ & $\begin{array}{c}0.15 \\
(0.10)\end{array}$ \\
\hline Observations & 52,097 & 52,616 & 42,705 & 41,797 \\
\hline Firm FE & $\checkmark$ & $\checkmark$ & $\checkmark$ & $\checkmark$ \\
\hline Year FE & $\checkmark$ & $\checkmark$ & $\checkmark$ & $\checkmark$ \\
\hline Age FE & $\checkmark$ & $\checkmark$ & $\checkmark$ & $\checkmark$ \\
\hline
\end{tabular}

Panel B: LP Classification

\begin{tabular}{lcccc} 
Reform $_{j t} \times I_{i}^{\text {High MRPL }}$ & 0.13 & $0.25^{*}$ & $0.31^{* * *}$ & $-0.35^{* * *}$ \\
& $(0.11)$ & $(0.14)$ & $(0.09)$ & $(0.11)$ \\
Reform $_{j t}$ & $0.18^{* * *}$ & $0.21^{* * *}$ & -0.00 & 0.14 \\
& $(0.05)$ & $(0.05)$ & $(0.11)$ & $(0.13)$ \\
& & & & \\
\hline Observations & 50,121 & 50,524 & 41,068 & 38,657 \\
Firm FE & $\checkmark$ & $\checkmark$ & $\checkmark$ & $\checkmark$ \\
Year FE & $\checkmark$ & $\checkmark$ & $\checkmark$ & $\checkmark$ \\
Age FE & $\checkmark$ & $\checkmark$ & $\checkmark$ & $\checkmark$ \\
\hline
\end{tabular}

This table reports estimates of the foreign capital liberalization reforms' effects on high and low pre-treatment MRPL firms (analoguous to equation (4), except substituting the high MRPL classification for high MRPK) over the period 1995-2015. All dependent variables are in logs. Re form for $_{\text {in }}$ is indicator variable equal to one if the industry has liberalized access to the foreign capital market. Firms are classified as high MRPL if their average MRPL in the pre-treatment period from 1995-2000 is above the 4-digit industry median. In Panel A, MRPL is calculated as $Y / L$. In Panel B, it is calculated by estimating the production function using Levinsohn and Petrin (2003) (LP). Standard errors are twoway clustered at the 4-digit industry and year level. * **, and $* * *$ denote $10 \%, 5 \%$, and $1 \%$ statistical significance respectively. 
Table 7: Effects of Foreign Capital Market Liberalization on the Solow Residual of Manufacturing

\begin{tabular}{lc}
\hline \hline & Increase in Solow Residual \\
\hline Lower Bound & $6.5 \%$ \\
Attributing All Cross-Sectional Variation & $159 \%$ \\
Measurement Error Correction (Top and Bottom 15\%) & $10.2 \%$ \\
\hline
\end{tabular}

This table reports the estimates of the effect of the foreign capital liberalizations in 2001 and 2006 on the manufacturing industry's Solow residual using a first order approximation (equation (2)). The estimates are generated using the Prowess data set. The first row gives the lower bound estimate, which assumes that the policy eliminated misallocation. The second row attributes all of the baseline variation in the marginal revenue products of inputs to misallocation. The third row does the same after winsorizing the top and bottom $15 \%$ of the marginal revenue products within industries. 


\section{Appendix A: Derivation of Aggregation Formula}

In this section, we derive equation (2), the formula used to approximate the change in the Solow residual due to the policy. We start by defining

$$
y_{i}=A_{i} f\left(y_{i j}\right)
$$

where $y_{i}$ is the output of firm $i, A_{i}$ is firm $i$ 's productivity, $f$ is the production function, and $y_{i j}$ is a vector of inputs to firm $i$, where $j$ denotes the firm that sold the input. Then, the total derivative of $y_{i}$ is

$$
d \log y_{i}=\sum_{j} \frac{\partial \log f_{i}}{\partial \log y_{i j}} d \log y_{i j}+d \log A_{i} .
$$

A firm $i$ solves the constrained cost minimization problem

$$
\mathcal{C}_{i}\left(p, y_{i}\right)=\sum_{j} p_{j} y_{i j}+\gamma_{i}\left(y_{i}-A_{i} f_{i}\left(y_{i}\right)\right)
$$

where $p$ is the vector of prices, $p_{j}$ is the price of a good produced by $j$, and $\gamma_{i}$ is the Lagrange multiplier. From the first order conditions of equation (11)

$$
p_{j}=\gamma_{i} A_{i} \frac{\partial f_{i}}{\partial y_{i j}}
$$

Then,

$$
\mu_{i}=\frac{p_{i}}{\partial \mathcal{C} / \partial y_{i}}=\frac{p_{i}}{\gamma_{i}}
$$

where $\mu_{i}$ is the mark-up of $i$, implying that $\gamma_{i}=\frac{p_{i}}{\mu_{i}}$. Substituting this relationship into (12) shows that $p_{j}=\frac{p_{i}}{\mu_{i}} A_{i} \frac{\partial f_{i}}{\partial y_{i}}$. Then

$$
\begin{aligned}
\frac{p_{j} y_{i j}}{p_{i} y_{i}} & =\frac{A_{i} y_{i j}}{\mu_{i} y_{i}} \frac{\partial f_{i}}{\partial y_{i j}} \\
& =\frac{\partial \log f_{i}}{\partial \log y_{i j}} \frac{1}{\mu_{i}}
\end{aligned}
$$

which can be rewritten as $\mu_{i} \frac{p_{j} y_{i j}}{p_{i} y_{i}}=\frac{\partial \log f_{i}}{\partial \log y_{i j}}$. Then, substituting this into the total derivative (equation (10)) produces

$$
d \log y_{i}=d \log A_{i}+\mu_{i} \sum_{j} \frac{p_{j} y_{i j}}{p_{i} y_{i}} d \log y_{i}
$$

Note that this implies that

$$
\frac{1}{\mu_{i}}\left(d \log y_{i}-d \log A_{i}\right)-\sum_{j \notin I} \frac{p_{j} y_{i j}}{p_{i} y_{i}} d \log y_{i j}=\sum_{j \in I} \frac{p_{j} y_{i j}}{p_{i} y_{i}} d \log y_{i j} .
$$

Now that we have these expressions, we can turn to deriving our object of interest. We define firm-level net output to be $c_{i}$ and total industry-level output to be $P C=\sum_{i \in I} p_{i} c_{i}$, 
where $c_{i}=y_{i}-\sum_{j \in I} y_{i j}$. Then

$$
d \log c_{i}=\frac{y_{i}}{c_{i}} d \log y_{i}-\sum_{j \in I} \frac{y_{i j}}{c_{i}} d \log y_{i j}
$$

and the change in industry-level net output is given by

$$
d \log C=\sum_{i} \frac{p_{i} c_{i}}{P C} d \log c_{i}=\sum_{i}\left(\frac{p_{i} y_{i}}{P C} d \log y_{i}-\sum_{j \in I} \frac{p_{i} y_{i j}}{P C} d \log y_{i j}\right) .
$$

Then, the change in the Solow residual for $I$ is approximated by

$$
\Delta \text { Solow }_{I} \approx d \log C-\sum_{i \in I} \sum_{j \notin I} \frac{p_{j} y_{i j}}{p_{i} y_{i}} \frac{p_{i} y_{i}}{P C} d \log y_{i j}
$$

Using equation (13), with a little algebra, we can rewrite this as

$$
\Delta \text { Solow }_{I} \approx \sum_{i \in I} \lambda_{i}\left(1-\frac{1}{\mu_{i}}\right)\left(d \log y_{i}-d \log A_{i}\right)+\sum_{i \in I} \lambda_{i} d \log A_{i},
$$

where $\lambda_{i}=\frac{p_{i} y_{i}}{P C}$. Now, we transform equation (14) to use input wedges instead of output wedges, so that it matches equation (2). First, we rewrite the output wedges $\left(\mu_{i}\right)$ as input wedges, consistent with the theoretical framework in Section 2. This allows us to rewrite equation (14) in terms of firm-level capital, labor, and materials wedges where each firm-input combination is a "producer". ${ }^{45}$ The wedge on firm $i$ 's input $x$ is $\tau_{i}^{x}$, and the price paid by the firm is $\left(1+\tau_{i}^{x}\right) p^{x}$, while the marginal cost of producing $x$ is $p^{x}$. The gross output wedge for producer $(x, i)$ is given by: $\mu_{i}^{x}=1+\tau_{i}^{x}$. Second, we define $\alpha_{i}^{x}$ to be the output elasticity of input $i$ with respect to input $x$. Then, for a given firm $i$, $d \log y_{i}-d \log A_{i}=\sum_{x \in\{k, l, m\}} \alpha_{i}^{x}$. So, we can rewrite equation (14) as:

$$
\Delta \text { Solow }_{I, t} \approx \sum_{i \in I} \lambda_{i} \Delta \log A_{i}+\sum_{\substack{i \in I \\ x \in\{k, l, m\}}} \lambda_{i} \alpha_{i}^{x} \tau_{i}^{x} \Delta \log x_{i}
$$

45. While equation (14) models wedges on output rather than inputs, this framework is general and input wedges can be thought of as a special case of this formulation. In particular, we can think of each input wedge for firm $i$ coming from a fictitious middleman firm that buys the input without a wedge and then sells it with an output wedge to firm $i$. 


\section{Appendix B: Estimating the Distribution of the Minimum Wedges}

In this appendix, we show that the difference-in-differences regressions with heterogeneous effects can be used to estimate the minimum wedge prior to the policy under the two assumptions outlined in the main text. We focus here on estimating $\tau_{\text {pre }}^{k}$, where the $i$ subscript is surpressed for notational simplicity. The reasoning is identical for labor and materials.

Denote $m r p k_{i}$ the true marginal revenue product of capital of firm $i$ (which is never observed) and $M R P K_{i}$ the marginal product of capital observed in the data with measurement error, such that we have:

$$
\log \left(M R P K_{i t}\right)=\log \left(m r p k_{i t}\right)+\mu_{i}+\eta_{t}+\epsilon_{i t}
$$

where $\epsilon_{i t}$ is a firm-period idiosyncratic error, $\mu_{i}$ is a firm-specific, time-invariant shock, and $\eta_{t}$ is a time-period specific shock.

Denote $T_{j}$ to be the time period of the reform in a disaggregated industry $j$. If a firm is in an industry that does not go through a reform $\left(\right.$ Reform $\left._{j}=0\right)$ or if the firm is in an industry that will be reformed but the reform has not taken place yet $\left(\right.$ Reform $_{j}=1$ and $\left.t<T_{j}\right)$ :

$$
\log \left(m r p k_{i j t}\right)=\log \left(1+\tau_{i t}^{k}\right)+\log \left(p_{t}^{k}\right)
$$

Under the assumption the policy has eliminated misallocation, if the firm is in an industry that is reformed and the reform has taken place, Reform $_{j}=1$ and $t>T_{j}$, then $\tau_{i t}^{k}=0$ and

$$
\log \left(m r p k_{i j t}\right)=\log \left(p_{t}^{k}\right) .
$$

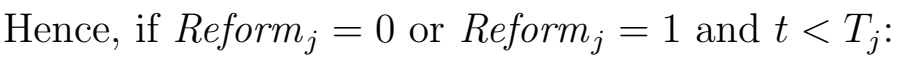

$$
\log \left(M R P K_{i j t}\right)=\log \left(1+\tau_{i t}^{k}\right)+\log \left(p_{t}^{k}\right)+\mu_{i}+\eta_{t}+\epsilon_{i t}
$$

For firms where Reform $_{j}=1$ and $t \geq T_{j}$

$$
\log \left(M R P K_{i j t}\right)=\log \left(p_{t}^{k}\right)+\mu_{i}+\eta_{t}+\epsilon_{i t}
$$

Denote $g_{i}\left(\right.$ Reform $\left._{j t}\right)$ to be a firm-specific function of the reform indicator variable, which can be written as a linear interaction between a vector of firm-level characteristics $\mathbf{X}_{\mathbf{i}}$ and the indicator variable Reform $_{j t}$. Then, the difference-in-differences regression estimates

$$
\log \left(M R P K_{i j t}\right)=g_{i}\left(\text { Reform }_{j t}\right)+\alpha_{i}+\delta_{t}+\epsilon_{i t} .
$$

In this regression, firm fixed effects absorb $\mu_{i}$, as well as any time invariant industry shocks, and time fixed effects absorb $\eta_{t}$ and $\log \left(p_{t}^{k}\right)$. Idiosyncratic shocks $\epsilon_{i t}$ are independent of Reform ${ }_{j t}$. Thus, $\hat{g}_{i}(1)$ is an unbiased estimator of $E\left(\log \left(1+\tau_{i t}\right)\right)$ over the pre-period and can be used to predict the average value of $\log \left(1+\tau_{i}^{k}\right)$ over the pre-period. 


\section{Appendix C: Applications of the Aggregation Method to Other Settings}

In this appendix, we discuss how researchers can apply the aggregation methodology in Section 7 to estimates from a natural experiment or an experiment in a different setting. As described in Section 7, to apply the lower bound methodology, the researcher must make two key assumptions: (1) the reform only reduced misallocation, and (2) spillovers across the unit of treatment (e.g. industries, geographic entities) are either nonexistent or can be measured using observable characteristics like input-output linkages or with the experimental design.

We consider two categories of settings where researchers may want to apply the aggregation methodology: (1) reductions in misallocation due to changes in the distribution of inputs within the treated group and (2) reductions in misallocation due to changes in inputs used by the treated group.

Reallocation Within the Treated Group The natural experiment studied in this paper falls into this category. In this case, there is a treatment at the unit $j$ level, which can potentially refer to an industry or a geographic region but could also refer to the whole treated group of firms. If the researcher believes that the treatment reduced misallocation by reducing wedges for firms with high wedges in unit $j$ and/or increasing wedges for firms with low wedges, she can apply a similar estimation strategy to the one used in Section 7.2 to estimate firm-level changes in inputs and wedges. To study cross-industry or cross-geography changes in misallocation, as opposed to the cross-firm changes in the same industry as we do, the researcher can allow $g_{i}$ to depend on industry or geographic unit-level characteristics as well as, or in place of, firm-level characteristics.

Changes in Inputs to the Treated Group In some cases, the design of a policy or an experiment may allow the researcher to assume the policy/treatment reduced misallocation even if the researcher is not interested in reallocation within the treated group. For example, if a policy that improves access to inputs is targeted toward firms with ex ante higher input wedges and increases input use for these firms, it may be reasonable for the researcher to assume the policy reduced misallocation. In this case, the researcher may not need to estimate heterogeneous treatment effects. The researcher could use the firm-level average treatment effect of the policy as an estimate of the wedges and changes in inputs for the treated group. 


\section{Appendix Tables}

Table A1: List of Industries that Changed Foreign Investment Polices Between 1995 and 2015

\begin{tabular}{|c|c|}
\hline $\begin{array}{l}\text { (1) } \\
\text { NIC 5-Digit Industry Classification }\end{array}$ & $\begin{array}{c}(2) \\
\text { Reform Year }\end{array}$ \\
\hline Manufacture of 'ayurvedic' or 'unani' pharmaceutical preparation & 2001 \\
\hline Manufacture of allopathic pharmaceutical preparations & 2001 \\
\hline Manufacture of homoeopathic or biochemic pharmaceutical preparations & 2001 \\
\hline Manufacture of other pharmaceutical and botanical products n.e.c. like hina powder etc. & 2001 \\
\hline Manufacture of rubber tyres and tubes n.e.c. & 2006 \\
\hline Manufacture of rubber tyres and tubes for cycles and cycle-rickshaws & 2006 \\
\hline Manufacture of distilled, potable, alcoholic beverages such as whisky, brandy, gin, 'mixed drinks' etc. & 2006 \\
\hline Coffee curing, roasting, grinding blending etc. and manufacturing of coffee products & 2006 \\
\hline Retreading of tyres; replacing or rebuilding of tread on used pneumatic tyres & 2006 \\
\hline Manufacture of chemical elements and compounds doped for use in electronics & 2006 \\
\hline Manufacture of country liquor & 2006 \\
\hline Manufacture of catechu(katha) and chewing lime & 2006 \\
\hline Stemming and redrying of tobacco & 2006 \\
\hline Manufacture of other rubber products n.e.c. & 2006 \\
\hline Manufacture of rubber contraceptives & 2006 \\
\hline Manufacture of other tobacco products including chewing tobacco n.e.c. & 2006 \\
\hline Manufacture of pan masala and related products. & 2006 \\
\hline
\end{tabular}

This table lists 5-digit NIC industries that changed to automatic foreign investment approval for investments up to (at least) $51 \%$ of a firm's capital and the year that the policy reform took place. 
Table A2: Heterogeneous Effects of Foreign Capital Liberalization: 5-Digit Industry-byYear Fixed Effects

\begin{tabular}{lccccc}
\hline Dependent Variable & Revenues & Capital & Wages & MRPK \\
\cline { 2 - 2 } & $\frac{(2)}{(1)}$ & $\frac{(3)}{(4)}$
\end{tabular}

\section{Panel A: Y/K Classification}

\begin{tabular}{lcccc} 
Reform $_{j t} \times I_{i}^{\text {High MRPK }}$ & $\begin{array}{c}0.32^{* * *} \\
(0.05)\end{array}$ & $\begin{array}{c}0.74^{* * *} \\
(0.08)\end{array}$ & $\begin{array}{c}0.43^{* * *} \\
(0.11)\end{array}$ & $\begin{array}{c}-0.40^{* * *} \\
(0.10)\end{array}$ \\
\hline Observations & 62,439 & 62,116 & 47,339 & 59,462 \\
Firm FE & $\checkmark$ & $\checkmark$ & $\checkmark$ & $\checkmark$ \\
5-Digit Industry-Year FE & $\checkmark$ & $\checkmark$ & $\checkmark$ & $\checkmark$ \\
Age FE & $\checkmark$ & $\checkmark$ & $\checkmark$ & $\checkmark$ \\
\hline
\end{tabular}

Panel B: LP Classification

\begin{tabular}{lcccc} 
Reform $_{j t} \times I_{i}^{\text {High MRPK }}$ & $\begin{array}{c}0.40^{* * *} \\
(0.09)\end{array}$ & $\begin{array}{c}0.63^{* * *} \\
(0.14)\end{array}$ & $\begin{array}{c}0.44^{* * *} \\
(0.10)\end{array}$ & $\begin{array}{c}-0.54^{* * *} \\
(0.10)\end{array}$ \\
\hline Observations & 49,322 & 48,932 & 39,428 & 37,005 \\
Firm FE & $\checkmark$ & $\checkmark$ & $\checkmark$ & $\checkmark$ \\
5-Digit Industry-Year FE & $\checkmark$ & $\checkmark$ & $\checkmark$ & $\checkmark$ \\
Age FE & $\checkmark$ & $\checkmark$ & $\checkmark$ & $\checkmark$ \\
\hline
\end{tabular}

This table reports estimates of the heterogeneous effects of the liberalization reforms on high MRPK firms in the Prowess data set (equation (4)). All dependent variables are in logs. Firms are observed between 1995 and 2015. All regressions include firm fixed effects, firm age fixed effects, and 5-digit industry-by-year fixed effects. Firms are classified as constrained if their average MRPK in the pretreatment period from 1995-2000 is above the 4-digit industry median. In Panel A, MRPK is calculated as $Y / K$. In Panel B, it is calculated by estimating the production function using LP. Standard errors are twoway clustered at the 4-digit industry and year level. *,**, and *** denote $10 \%, 5 \%$, and $1 \%$ statistical significance respectively. 
Table A3: Robustness of Heterogeneous Effects of Foreign Capital Liberalization to Inclusion of 2-Digit Industry-by-Year FE

\begin{tabular}{|c|c|c|c|c|}
\hline \multirow[t]{2}{*}{ Dependent Variable } & Revenues & Capital & Wages & MRPK \\
\hline & (1) & $(2)$ & (3) & (4) \\
\hline
\end{tabular}

Panel A: Y/K Classification

$\begin{array}{lcccc}\text { Reform }_{j t} \times I_{i}^{\text {High MRPK }} & \begin{array}{c}0.20^{* * *} \\ (0.05)\end{array} & \begin{array}{c}0.61^{* * *} \\ (0.08)\end{array} & \begin{array}{c}0.29^{* *} \\ (0.11)\end{array} & \begin{array}{c}-0.40^{* * *} \\ (0.09)\end{array} \\ \text { Reform }_{j t} & \begin{array}{c}0.01 \\ (0.11)\end{array} & \begin{array}{c}-0.13 \\ (0.14)\end{array} & \begin{array}{c}-0.11 \\ (0.11)\end{array} & \begin{array}{c}0.13 \\ \end{array} \\ & 64,009 & 63,697 & 48,968 & 61,061 \\ & \checkmark & \checkmark & \checkmark & \checkmark \\ \text { Observations } & \checkmark & \checkmark & \checkmark & \checkmark \\ \text { Firm FE } & \checkmark & \checkmark & \checkmark & \checkmark \\ \text { 2-Digit Industry-Year FE } & & & & \\ \text { Age FE } & & & & \end{array}$

Panel B: LP Classification

\begin{tabular}{lcccc} 
Reform $_{j t} \times I_{i}^{\text {High MRPK }}$ & $\begin{array}{c}0.27^{* *} \\
(0.09)\end{array}$ & $\begin{array}{c}0.48^{* * *} \\
(0.15)\end{array}$ & $\begin{array}{c}0.33^{* * *} \\
(0.12)\end{array}$ & $\begin{array}{c}-0.55^{* * *} \\
(0.11)\end{array}$ \\
Reform $_{j t}$ & $\begin{array}{c}-0.03 \\
(0.12)\end{array}$ & $\begin{array}{c}-0.03 \\
(0.18)\end{array}$ & $\begin{array}{c}-0.14 \\
(0.09)\end{array}$ & $\begin{array}{c}0.14 \\
\end{array}$ \\
& & & & \\
\hline Observations & 50,857 & 50,454 & 41,006 & 38,595 \\
Firm FE & $\checkmark$ & $\checkmark$ & $\checkmark$ & $\checkmark$ \\
2-Digit Industry-Year FE & $\checkmark$ & $\checkmark$ & $\checkmark$ & $\checkmark$ \\
Age FE & $\checkmark$ & $\checkmark$ & $\checkmark$ & $\checkmark$ \\
\hline
\end{tabular}

This table reports estimates of the heterogeneous effects of foreign capital liberalization reforms on high and low MRPK firms in the Prowess data set (equation (4)). All dependent variables are in logs. Firms are observed between 1995 and 2015. All regressions include firm fixed effects, firm age fixed effects, and 2-digit industry-by-year fixed effects. Firms are classified as constrained if their average MRPK in the pre-treatment period from 1995-2000 is above the 4-digit industry median. In Panel A, MRPK is calculated as $Y / K$. In Panel B, it is calculated by estimating the production function using LP. Standard errors are twoway clustered at the 4-digit industry and year level. *, **, and *** denote 10, 5, and $1 \%$ statistical significance respectively. 
Table A4: Robustness of Heterogeneous Effects of Foreign Capital Liberalization: Stateby-Year and Size Controls

\begin{tabular}{|c|c|c|c|c|c|c|c|c|}
\hline \multirow[t]{2}{*}{ Dependent Variable } & \multicolumn{2}{|c|}{ Revenues } & \multicolumn{2}{|c|}{ Capital } & \multicolumn{2}{|c|}{ Wages } & \multicolumn{2}{|c|}{ MRPK } \\
\hline & $(1)$ & $(2)$ & $(3)$ & $(4)$ & $(5)$ & $(6)$ & $(7)$ & $(8)$ \\
\hline
\end{tabular}

\section{Panel A: Y/K Classification}

\begin{tabular}{|c|c|c|c|c|c|c|c|c|}
\hline Reform $_{j t} \times I_{i}^{\text {High } M R P K}$ & $\begin{array}{c}0.16^{* * *} \\
(0.06)\end{array}$ & $\begin{array}{c}0.24^{* * *} \\
(0.06)\end{array}$ & $\begin{array}{c}0.56^{* * *} \\
(0.14)\end{array}$ & $\begin{array}{c}0.51^{* * *} \\
(0.07)\end{array}$ & $\begin{array}{l}0.22 * \\
(0.11)\end{array}$ & $\begin{array}{c}0.22^{* *} \\
(0.10)\end{array}$ & $\begin{array}{c}-0.42^{* * *} \\
(0.09)\end{array}$ & $\begin{array}{c}-0.31^{* * *} \\
(0.12)\end{array}$ \\
\hline Reform $_{j t}$ & $\begin{array}{c}0.12 \\
(0.09)\end{array}$ & $\begin{array}{c}0.10 \\
(0.08)\end{array}$ & $\begin{array}{c}0.00 \\
(0.09)\end{array}$ & $\begin{array}{c}0.06 \\
(0.08)\end{array}$ & $\begin{array}{c}0.01 \\
(0.018\end{array}$ & $\begin{array}{c}0.03 \\
(0.09)\end{array}$ & $\begin{array}{c}0.04 \\
(0.13)\end{array}$ & $\begin{array}{l}-0.06 \\
(0.13)\end{array}$ \\
\hline $\operatorname{Reform}_{j t} \times \log ($ Size $)$ & & $\begin{array}{l}-0.03 \\
(0.02)\end{array}$ & & $\begin{array}{l}-0.01 \\
(0.02)\end{array}$ & & $\begin{array}{l}-0.00 \\
(0.02)\end{array}$ & & $\begin{array}{c}0.00 \\
(0.03)\end{array}$ \\
\hline Observations & 64,009 & 64,009 & 63,697 & 63,697 & 48,968 & 48,968 & 61,061 & 61,061 \\
\hline Firm FE & $\checkmark$ & $\checkmark$ & $\checkmark$ & $\checkmark$ & $\checkmark$ & $\checkmark$ & $\checkmark$ & $\checkmark$ \\
\hline State $\times$ Year FE & $\checkmark$ & - & $\checkmark$ & - & $\checkmark$ & - & $\checkmark$ & - \\
\hline Size Decile $\times$ Year FE & - & $\checkmark$ & - & $\checkmark$ & - & $\checkmark$ & - & $\checkmark$ \\
\hline Age FE & $\checkmark$ & $\checkmark$ & $\checkmark$ & $\checkmark$ & $\checkmark$ & $\checkmark$ & $\checkmark$ & $\checkmark$ \\
\hline
\end{tabular}

Panel B: LP Classification

\begin{tabular}{|c|c|c|c|c|c|c|c|c|}
\hline Reform $_{j t} \times I_{i}^{\text {High } M R P K}$ & $\begin{array}{c}0.22^{* *} \\
(0.10)\end{array}$ & $\begin{array}{c}0.25^{* *} \\
(0.10)\end{array}$ & $\begin{array}{c}0.41^{* * *} \\
(0.14)\end{array}$ & $\begin{array}{c}0.34^{* *} \\
(0.13)\end{array}$ & $\begin{array}{c}0.26^{* *} \\
(0.12)\end{array}$ & $\begin{array}{c}0.26^{* *} \\
(0.10)\end{array}$ & $\begin{array}{c}-0.57^{* * *} \\
(0.12)\end{array}$ & $\begin{array}{c}-0.47^{* * *} \\
(0.10)\end{array}$ \\
\hline Reform $_{j t}$ & $\begin{array}{c}0.11 \\
(0.08)\end{array}$ & $\begin{array}{c}0.12 \\
(0.08)\end{array}$ & $\begin{array}{c}0.12 \\
(0.08)\end{array}$ & $\begin{array}{c}0.18^{* *} \\
(0.08)\end{array}$ & $\begin{array}{c}0.00 \\
(0.08)\end{array}$ & $\begin{array}{c}0.03 \\
(0.09)\end{array}$ & $\begin{array}{c}0.19 \\
(0.12)\end{array}$ & $\begin{array}{c}0.09 \\
(0.14)\end{array}$ \\
\hline $\operatorname{Reform~}_{j t} \times \log ($ Size $)$ & & $\begin{array}{c}-0.03 \\
(0.03)\end{array}$ & & $\begin{array}{c}0.02 \\
(0.02)\end{array}$ & & $\begin{array}{c}-0.01 \\
(0.02)\end{array}$ & & $\begin{array}{l}-0.00 \\
(0.03)\end{array}$ \\
\hline Observations & 50,857 & 50,857 & 50,454 & 50,454 & 41,006 & 41,006 & 38,595 & 38,595 \\
\hline Firm FE & $\checkmark$ & $\checkmark$ & $\checkmark$ & $\checkmark$ & $\checkmark$ & $\checkmark$ & $\checkmark$ & $\checkmark$ \\
\hline State $\times$ Year FE & $\checkmark$ & - & $\checkmark$ & - & $\checkmark$ & - & $\checkmark$ & - \\
\hline Size Decile $\times$ Year FE & - & $\checkmark$ & - & $\checkmark$ & - & $\checkmark$ & - & $\checkmark$ \\
\hline Age FE & $\checkmark$ & $\checkmark$ & $\checkmark$ & $\checkmark$ & $\checkmark$ & $\checkmark$ & $\checkmark$ & $\checkmark$ \\
\hline
\end{tabular}

This table reports estimates of the heterogeneous effects of foreign capital liberalization reforms on high and low MRPK firms in the Prowess dataset (equation (4)). Dependent variables are in logs. Firms are observed between 1995 and 2015. All regressions include firm fixed effects and firm age fixed effects. Odd columns include state-by-year fixed effects, and even columns include size decile-by-year fixed effects, as well as the interaction between $R e$ form $_{j t}$ and log firm size. Size is computed as the average sales between 1995 and 2000. Firms are classified as constrained if their average MRPK in the pre-treatment period from 1995-2000 is above the 4-digit industry median. In Panel A, MRPK is approximated as $Y / K$. In Panel B, it is calculated by estimating the production function using LP. Standard errors are twoway clustered at the 4-digit industry and year level. *, **, and *** denote 10, 5, and $1 \%$ statistical significance respectively. 
Table A5: Robustness of Heterogeneous Effects of Foreign Capital Liberalization: Accounting for Dereservation

\begin{tabular}{|c|c|c|c|c|}
\hline Dependent Variable & Revenues & Capital & Wages & MRPK \\
\hline & (1) & $(3)$ & $(5)$ & $(7)$ \\
\hline
\end{tabular}

\begin{tabular}{|c|c|c|c|c|c|c|c|c|}
\hline \multirow[b]{2}{*}{ Reform $_{j t} \times I_{i}^{\text {High MRPK }}$} & \multicolumn{8}{|c|}{ Panel A: Y/K Classification } \\
\hline & $\begin{array}{c}0.20^{* * *} \\
(0.03)\end{array}$ & $\begin{array}{c}0.19^{* * *} \\
(0.05)\end{array}$ & $\begin{array}{c}0.67^{* * *} \\
(0.05)\end{array}$ & $\begin{array}{c}0.55^{* * *} \\
(0.10)\end{array}$ & $\begin{array}{c}0.41^{* * *} \\
(0.09)\end{array}$ & $\begin{array}{c}0.25^{* *} \\
(0.12)\end{array}$ & $\begin{array}{c}-0.48^{* * *} \\
(0.06)\end{array}$ & $\begin{array}{c}-0.38^{* * *} \\
(0.11)\end{array}$ \\
\hline Reform $_{j t}$ & $\begin{array}{l}0.22^{* *} \\
(0.08)\end{array}$ & $\begin{array}{c}0.13 \\
(0.09)\end{array}$ & $\begin{array}{c}0.00 \\
(0.09)\end{array}$ & $\begin{array}{l}-0.02 \\
(0.07)\end{array}$ & $\begin{array}{l}-0.00 \\
(0.11)\end{array}$ & $\begin{array}{l}-0.01 \\
(0.09)\end{array}$ & $\begin{array}{c}0.06 \\
(0.13)\end{array}$ & $\begin{array}{c}0.04 \\
(0.12)\end{array}$ \\
\hline Sample: No dereservation & $\checkmark$ & - & $\checkmark$ & - & $\checkmark$ & - & $\checkmark$ & - \\
\hline Dereservation Controls & - & $\checkmark$ & - & $\checkmark$ & - & $\checkmark$ & - & $\checkmark$ \\
\hline Observations & 28,987 & 64,022 & 28,760 & 63,704 & 22,110 & 48,983 & 27,496 & 61,081 \\
\hline Firm FE & $\checkmark$ & $\checkmark$ & $\checkmark$ & $\checkmark$ & $\checkmark$ & $\checkmark$ & $\checkmark$ & $\checkmark$ \\
\hline Year FE & $\checkmark$ & $\checkmark$ & $\checkmark$ & $\checkmark$ & $\checkmark$ & $\checkmark$ & $\checkmark$ & $\checkmark$ \\
\hline Age FE & $\checkmark$ & $\checkmark$ & $\checkmark$ & $\checkmark$ & $\checkmark$ & $\checkmark$ & $\checkmark$ & $\checkmark$ \\
\hline
\end{tabular}

Panel B: LP Classification

\begin{tabular}{lcccccccc} 
Reform $_{j t} \times I_{i}^{\text {High MRPK }}$ & $0.29^{* * *}$ & $0.21^{* *}$ & $0.61^{* * *}$ & $0.40^{*}$ & $0.45^{* * *}$ & $0.29^{* *}$ & $-0.62^{* * *}$ & $-0.50^{* * *}$ \\
& $(0.07)$ & $(0.10)$ & $(0.08)$ & $(0.20)$ & $(0.09)$ & $(0.12)$ & $(0.06)$ & $(0.13)$ \\
Reform $_{j t}$ & $0.23^{* *}$ & 0.14 & 0.11 & 0.10 & 0.03 & -0.01 & 0.19 & 0.18 \\
& $(0.09)$ & $(0.08)$ & $(0.09)$ & $(0.07)$ & $(0.11)$ & $(0.08)$ & $(0.14)$ & $(0.11)$ \\
\hline Sample: No dereservation & $\checkmark$ & - & $\checkmark$ & - & $\checkmark$ & - & $\checkmark$ & - \\
Dereservation Controls & - & $\checkmark$ & - & $\checkmark$ & - & $\checkmark$ & - & $\checkmark$ \\
Observations & 22,642 & 50,874 & 22,421 & 50,478 & 18,203 & 41,035 & 17,079 & 38,613 \\
Firm FE & $\checkmark$ & $\checkmark$ & $\checkmark$ & $\checkmark$ & $\checkmark$ & $\checkmark$ & $\checkmark$ & $\checkmark$ \\
Year FE & $\checkmark$ & $\checkmark$ & $\checkmark$ & $\checkmark$ & $\checkmark$ & $\checkmark$ & $\checkmark$ & $\checkmark$ \\
Age FE & $\checkmark$ & $\checkmark$ & $\checkmark$ & $\checkmark$ & $\checkmark$ & $\checkmark$ & $\checkmark$ & $\checkmark$ \\
\hline
\end{tabular}

This table reports estimates of the heterogeneous effects of foreign capital liberalization reforms on high and low MRPK firms in the Prowess dataset (equation (4)), accounting for dereservation policies. Firms are observed between 1995 and 2015. All regressions include firm, year and firm age fixed effects. In odd columns, we restrict the sample to firms in industries not affected by a dereservation policy after 2000 (i.e. a change in regulation specific to small and medium size firms). Data on dereservation events come from Boehm, Dhingra, and Morrow (2019). In even columns, we include the whole sample but interact $I_{i}^{H i g h} M R P K$ with an indicator variable Dereservation ${ }_{j t}$ that is equal to 1 after the industry has been deregulated. Firms are classified as constrained if their average MRPK in the pre-treatment period from 1995-2000 is above the industry median. In Panel A, MRPK is approximated as $Y / K$. In Panel B, it is calculated by estimating the production function using LP. Standard errors are twoway clustered at the 4-digit industry and year level. ${ }^{*}, * *$, and ${ }^{* * *}$ denote 10,5 , and $1 \%$ statistical significance respectively. 
Table A6: Effect of Foreign Capital Liberalization, Controlling for Tariffs

\begin{tabular}{|c|c|c|c|c|c|c|c|c|}
\hline \multirow[t]{2}{*}{ Dependent Variable } & \multicolumn{2}{|c|}{ Revenues } & \multicolumn{2}{|c|}{ Capital } & \multicolumn{2}{|c|}{ Wages } & \multicolumn{2}{|c|}{ MRPK } \\
\hline & (1) & (2) & (3) & $(4)$ & (5) & (6) & (7) & (8) \\
\hline
\end{tabular}

\begin{tabular}{|c|c|c|c|c|c|c|c|c|}
\hline \multirow[b]{2}{*}{$\begin{array}{l}\text { Reform }_{j t} \times I_{i}^{\text {High MRPK }} \\
\text { Reform }_{j t}\end{array}$} & \multicolumn{8}{|c|}{ Panel A: Y/K Classification } \\
\hline & $\begin{array}{c}0.17^{* * *} \\
(0.05) \\
0.24^{* *} \\
(0.10)\end{array}$ & $\begin{array}{c}0.13^{* *} \\
(0.06) \\
0.30^{*} \\
(0.15)\end{array}$ & $\begin{array}{c}0.59^{* * *} \\
(0.07) \\
0.12 \\
(0.11)\end{array}$ & $\begin{array}{c}0.57^{* * *} \\
(0.08) \\
0.13 \\
(0.17)\end{array}$ & $\begin{array}{c}0.24^{* *} \\
(0.11) \\
0.20^{*} \\
(0.11)\end{array}$ & $\begin{array}{c}0.19^{* *} \\
(0.08) \\
0.17 \\
(0.13)\end{array}$ & $\begin{array}{c}-0.43^{* * *} \\
(0.08) \\
-0.03 \\
(0.13)\end{array}$ & $\begin{array}{c}-0.41^{* * *} \\
(0.13) \\
0.09 \\
(0.13)\end{array}$ \\
\hline Observations & 64,022 & 64,022 & 63,704 & 63,704 & 48,983 & 48,983 & 61,081 & 61,081 \\
\hline Output Tariff Controls & $\checkmark$ & $\checkmark$ & $\checkmark$ & $\checkmark$ & $\checkmark$ & $\checkmark$ & $\checkmark$ & $\checkmark$ \\
\hline Input Tariff Controls & - & $\checkmark$ & - & $\checkmark$ & - & $\checkmark$ & - & $\checkmark$ \\
\hline Firm FE & $\checkmark$ & $\checkmark$ & $\checkmark$ & $\checkmark$ & $\checkmark$ & $\checkmark$ & $\checkmark$ & $\checkmark$ \\
\hline Year FE & $\checkmark$ & $\checkmark$ & $\checkmark$ & $\checkmark$ & $\checkmark$ & $\checkmark$ & $\checkmark$ & $\checkmark$ \\
\hline \multirow[t]{2}{*}{ Age FE } & $\checkmark$ & $\checkmark$ & $\checkmark$ & $\checkmark$ & $\checkmark$ & $\checkmark$ & $\checkmark$ & $\checkmark$ \\
\hline & \multicolumn{8}{|c|}{ Panel B: LP Classification } \\
\hline $\begin{array}{l}\text { Reform }_{j t} \times I_{i}^{\text {High MRPK }} \\
\text { Reform }_{j t}\end{array}$ & $\begin{array}{c}0.21^{* *} \\
(0.10) \\
0.28^{* * *} \\
(0.10)\end{array}$ & $\begin{array}{l}0.15^{*} \\
(0.08) \\
0.32^{* *} \\
(0.15)\end{array}$ & $\begin{array}{c}0.43^{* *} \\
(0.16) \\
0.28^{* * *} \\
(0.08)\end{array}$ & $\begin{array}{c}0.37^{* * *} \\
(0.12) \\
0.33^{* *} \\
(0.12)\end{array}$ & $\begin{array}{l}0.26^{* *} \\
(0.12) \\
0.22^{* *} \\
(0.09)\end{array}$ & $\begin{array}{c}0.22^{* * *} \\
(0.07) \\
0.20 \\
(0.12)\end{array}$ & $\begin{array}{c}-0.54^{* * *} \\
(0.11) \\
0.10 \\
(0.14)\end{array}$ & $\begin{array}{c}-0.43^{* * *} \\
(0.12) \\
0.07 \\
(0.12)\end{array}$ \\
\hline Observations & 47,463 & 38,370 & 47,171 & 38,357 & 40,277 & 38,061 & 37,912 & 35,878 \\
\hline Output Tariff Controls & $\checkmark$ & $\checkmark$ & $\checkmark$ & $\checkmark$ & $\checkmark$ & $\checkmark$ & $\checkmark$ & $\checkmark$ \\
\hline Input Tariff Controls & - & $\checkmark$ & - & $\checkmark$ & - & $\checkmark$ & - & $\checkmark$ \\
\hline Firm FE & $\checkmark$ & $\checkmark$ & $\checkmark$ & $\checkmark$ & $\checkmark$ & $\checkmark$ & $\checkmark$ & $\checkmark$ \\
\hline Year FE & $\checkmark$ & $\checkmark$ & $\checkmark$ & $\checkmark$ & $\checkmark$ & $\checkmark$ & $\checkmark$ & $\checkmark$ \\
\hline Age FE & $\checkmark$ & $\checkmark$ & $\checkmark$ & $\checkmark$ & $\checkmark$ & $\checkmark$ & $\checkmark$ & $\checkmark$ \\
\hline
\end{tabular}

This table reports estimates of the foreign capital liberalization on high and low pre-treatment MRPK firms (equation (4)) over the period 1995-2015, controlling for the effects of tariff policies and allowing those tariff policies to have differential effects by high and low MRPK. All dependent variables are in logs. Reform $_{j t}$ is an indicator variable equal to one if the industry has liberalized access to international capital market. Firms are classified as high MRPK if their average MRPK in the pre-treatment period from 1995-2000 is above the 4-digit industry median. Tariff data from 1995-2010 are constructed following Goldberg, Khandelwal, Pavcnik, and Topalova (2010), and tariff levels are coded at the 2010 level from 2010-2015. Output tariff controls are the average tarriff on an industry and its interaction with $I_{i}^{\text {High } M R P K}$. Input tariff controls are the average tariff on the inputs used by an industry and its interaction with $I_{i}^{H i g h} M R P K$. Standard errors are twoway clustered at the 4-digit industry and year level. ${ }^{*}, *$, and ${ }^{* * *}$ denote $10 \%, 5 \%$, and $1 \%$ statistical significance respectively. 
Table A7: Robustness of Heterogeneous Effects of Foreign Capital Liberalization to Using a Balanced Panel of Firms

\begin{tabular}{lccccc}
\hline \hline Dependent Variable & Revenues & Capital & Wages & MRPK \\
\cline { 2 - 2 } & $(1)$ & & $\frac{(2)}{(3)}$ & $\frac{(4)}{2}$ \\
\hline
\end{tabular}

Panel A: Y/K Classification

\begin{tabular}{lcccc} 
Reform $_{j t} \times I_{i}^{\text {High MRPK }}$ & $0.25^{*}$ & $0.47^{* * *}$ & 0.04 & $-0.24^{* *}$ \\
& $(0.14)$ & $(0.05)$ & $(0.09)$ & $(0.10)$ \\
Reform $_{j t}$ & 0.03 & 0.04 & 0.08 & -0.10 \\
& $(0.15)$ & $(0.12)$ & $(0.09)$ & $(0.12)$ \\
& & & & \\
\hline Observations & 29,975 & 29,640 & 23,601 & 29,131 \\
Firm FE & $\checkmark$ & $\checkmark$ & $\checkmark$ & $\checkmark$ \\
Year FE & $\checkmark$ & $\checkmark$ & $\checkmark$ & $\checkmark$ \\
Age FE & $\checkmark$ & $\checkmark$ & $\checkmark$ & $\checkmark$ \\
\hline
\end{tabular}

Panel B: LP Classification

\begin{tabular}{lcccc} 
Reform $_{j t} \times I_{i}^{\text {High MRPK }}$ & $\begin{array}{c}0.26^{*} \\
(0.15)\end{array}$ & $\begin{array}{c}0.36^{* *} \\
(0.17)\end{array}$ & $\begin{array}{c}0.21 \\
(0.12)\end{array}$ & $\begin{array}{c}-0.31^{* * *} \\
(0.10)\end{array}$ \\
Reform $_{j t}$ & 0.05 & 0.13 & -0.02 & 0.03 \\
& $(0.12)$ & $(0.08)$ & $(0.09)$ & $(0.12)$ \\
& & & & \\
\hline Observations & 25,624 & 25,338 & 20,452 & 19,642 \\
Firm FE & $\checkmark$ & $\checkmark$ & $\checkmark$ & $\checkmark$ \\
Year FE & $\checkmark$ & $\checkmark$ & $\checkmark$ & $\checkmark$ \\
Age FE & $\checkmark$ & $\checkmark$ & $\checkmark$ & $\checkmark$ \\
\hline
\end{tabular}

This table reports estimates of the heterogeneous effects of foreign capital liberalization on capital constrained and unconstrained firms in a balanced panel of firms that appear in both 1995 and 2015 from the Prowess data set (equation (4)). Dependent variables are in logs. Firms are observed between 1995 and 2015. All regressions include firm fixed effects, survey year fixed effects, and firm age fixed effects. Firms are classified as constrained if their average MRPK in the pre-treatment period from 1995-2000 is above the 4-digit industry median. In Panel A, MRPK is calculated as $Y / K$. In Panel $\mathrm{B}$, it is calculated by estimating the production function using the LP method. Standard errors are twoway clustered at the 4 -digit industry and year level. ${ }^{*},{ }^{* *}$, and ${ }^{* * *}$ denote $10 \%, 5 \%$, and $1 \%$ statistical significance respectively. 
Table A8: Effects of Foreign Capital Liberalization on Firm Exit and Entry

\begin{tabular}{|c|c|c|c|c|c|c|}
\hline \multirow[t]{2}{*}{ Dependent Variable } & \multicolumn{3}{|c|}{ Number of Exits } & \multicolumn{3}{|c|}{ Number of Entrants } \\
\hline & (1) & (2) & (3) & (4) & (5) & (6) \\
\hline \multirow[t]{2}{*}{ Reform $_{j t}$} & 0.16 & $0.06^{* *}$ & 0.04 & $-0.01^{* * *}$ & -0.01 & -0.01 \\
\hline & $(0.34)$ & $(0.03)$ & $(0.06)$ & $(0.00)$ & $(0.01)$ & $(0.01)$ \\
\hline $\operatorname{Reform}_{j t} \times I_{i}^{\text {High MRPK }}(\mathrm{Y} / \mathrm{K})$ & & $\begin{array}{l}-0.03 \\
(0.03)\end{array}$ & & & $\begin{array}{l}-0.00 \\
(0.00)\end{array}$ & \\
\hline Reform $_{j t} \times I_{i}^{\text {High MRPK }}(\mathrm{LP})$ & & & $\begin{array}{l}-0.00 \\
(0.02)\end{array}$ & & & $\begin{array}{l}0.00 \\
(0.00)\end{array}$ \\
\hline Observations & 8,190 & 12,411 & 11,025 & 8,190 & 12,411 & 11,025 \\
\hline Industry Fixed Effects & $\checkmark$ & $\checkmark$ & $\checkmark$ & $\checkmark$ & $\checkmark$ & $\checkmark$ \\
\hline Year Fixed Effects & $\checkmark$ & $\checkmark$ & $\checkmark$ & $\checkmark$ & $\checkmark$ & $\checkmark$ \\
\hline High MPRK Control & - & $\checkmark$ & $\checkmark$ & - & $\checkmark$ & $\checkmark$ \\
\hline
\end{tabular}

This table estimates the effect of the foreign capital liberalization on firm exit and entry in the Prowess data. In columns 1 and 5, an observation is a 5-digit industry-year cell. In the remaining columns, it is a 5-digit industry-year-MRPK category cell. A firm is counted as exiting in a year if it is not observed in the data in that year and does not re-enter the data in a later year. A firm is counted as entering in a year if that is the year of the firm's incorporation. Firms are classified as high MRPK if their average MRPK in the pre-treatment period from 1995-2000 is above the 4-digit industry median. In columns 2 and 5 , MRPK is calculated as $Y / K$. In columns 3 and 6 , it is calculated by estimating the production function using the LP method.Standard errors are twoway clustered at the 4-digit industry and year level. 
Table A9: Robustness of Heterogeneous Effects of Foreign Capital Liberalization to ACF Classification

\begin{tabular}{|c|c|c|c|c|}
\hline Dependent Variable & Revenues & Capital & Wages & MRPK \\
\hline & (1) & $(2)$ & $(3)$ & (4) \\
\hline Reform $_{j t} \times I_{i}^{H i g h M R P K}$ & $\begin{array}{c}0.19 \\
(0.16)\end{array}$ & $\begin{array}{c}0.65^{* * *} \\
(0.16)\end{array}$ & $\begin{array}{c}0.37^{* * *} \\
(0.09)\end{array}$ & $\begin{array}{c}-0.52^{* * *} \\
(0.16)\end{array}$ \\
\hline Reform $_{j t}$ & $\begin{array}{c}0.27^{*} \\
(0.14)\end{array}$ & $\begin{array}{c}0.07 \\
(0.13)\end{array}$ & $\begin{array}{c}0.13 \\
(0.11)\end{array}$ & $\begin{array}{c}0.08 \\
(0.22)\end{array}$ \\
\hline Observations & 18,378 & 18,613 & 16,286 & 12,356 \\
\hline Firm FE & $\checkmark$ & $\checkmark$ & $\checkmark$ & $\checkmark$ \\
\hline Year FE & $\checkmark$ & $\checkmark$ & $\checkmark$ & $\checkmark$ \\
\hline Age FE & $\checkmark$ & $\checkmark$ & $\checkmark$ & $\checkmark$ \\
\hline
\end{tabular}

This table reports estimates of the effect of the foreign capital liberalization on high and low pre-treatment MRPK firms (equation (4)) over the period 1995-2015. All dependent variables are in logs. Re form $_{j t}$ is an indicator variable equal to one if the industry has liberalized access to international capital market. Firms are classified as high MRPK if their average MRPK in the pre-treatment period from 1995-2000 is above the 4-digit industry median. MRPK is calculated by estimating the production function using ACF. Standard errors are twoway clustered at the 4-digit industry and year level. *, **, and ${ }^{* * *}$ denote $10 \%, 5 \%$, and $1 \%$ statistical significance respectively. 
Table A10: Robustness of Heterogeneous Effects of Foreign Capital Liberalization to Estimates From Quantity Production Functions

\begin{tabular}{|c|c|c|c|c|}
\hline \multirow[t]{2}{*}{ Dependent Variable } & Revenues & Capital & Wages & MRPK \\
\hline & (1) & (2) & (3) & (4) \\
\hline Reform $_{j t} \times I_{i}^{\text {High MRPK }}$ & $\begin{array}{c}0.21^{* *} \\
(0.09)\end{array}$ & $\begin{array}{c}0.45^{* * *} \\
(0.12)\end{array}$ & $\begin{array}{l}0.15^{*} \\
(0.08)\end{array}$ & $\begin{array}{c}-0.49^{* * *} \\
(0.10)\end{array}$ \\
\hline Reform $_{j t}$ & $\begin{array}{c}0.18 \\
(0.11)\end{array}$ & $\begin{array}{l}0.20^{*} \\
(0.11)\end{array}$ & $\begin{array}{c}0.15 \\
(0.11)\end{array}$ & $\begin{array}{c}0.18^{* *} \\
(0.07)\end{array}$ \\
\hline Observations & 32,339 & 32,557 & 26,257 & 19,605 \\
\hline Firm FE & $\checkmark$ & $\checkmark$ & $\checkmark$ & $\checkmark$ \\
\hline Year FE & $\checkmark$ & $\checkmark$ & $\checkmark$ & $\checkmark$ \\
\hline Age FE & $\checkmark$ & $\checkmark$ & $\checkmark$ & $\checkmark$ \\
\hline
\end{tabular}

This table reports estimates of the effect of foreign capital liberalization on high and low pre-treatment MRPK firms (equation (4)) over the period 1995-2015. All dependent variables are in logs. Reform fit $_{j t}$ an indicator variable equal to one if the industry has liberalized access to international capital market. Firms are classified as high MRPK if their average MRPK in the pre-treatment period from 1995-2000 is above the 4-digit industry median. MRPK is calculated by estimating the production function using quantities data using Levinsohn-Petrin. Standard errors are twoway clustered at the 4-digit industry and year level. *, **, and ${ }^{* * *}$ denote $10 \%, 5 \%$, and $1 \%$ statistical significance respectively. 
Table A11: Average Effect of Foreign Capital Market Liberalization, Accounting for Cross-Industry Spillover Effects

\begin{tabular}{|c|c|c|c|c|}
\hline \multirow[t]{2}{*}{ Dependent Variable } & Revenues & Capital & Wages & MRPK \\
\hline & (1) & $(2)$ & $(3)$ & $(4)$ \\
\hline Reform $_{j t}$ & $\begin{array}{c}0.23^{* * *} \\
(0.06)\end{array}$ & $\begin{array}{c}0.25^{* * *} \\
(0.09)\end{array}$ & $\begin{array}{c}0.11 \\
(0.09)\end{array}$ & $\begin{array}{l}-1.08 \\
(0.94)\end{array}$ \\
\hline Upstream $_{j t}$ & $\begin{array}{l}-0.38 \\
(0.35)\end{array}$ & $\begin{array}{l}-0.12 \\
(0.25)\end{array}$ & $\begin{array}{l}-0.30 \\
(0.24)\end{array}$ & $\begin{array}{l}-0.22 \\
(0.21)\end{array}$ \\
\hline Downstream $_{j t}$ & $\begin{array}{c}0.24 \\
(0.23)\end{array}$ & $\begin{array}{c}0.05 \\
(0.13)\end{array}$ & $\begin{array}{c}0.40 \\
(0.27)\end{array}$ & $\begin{array}{c}0.17 \\
(0.15)\end{array}$ \\
\hline Observations & 54,081 & 54,905 & 40,234 & 52,633 \\
\hline Firm Age FE & $\checkmark$ & $\checkmark$ & $\checkmark$ & $\checkmark$ \\
\hline Firm FE & $\checkmark$ & $\checkmark$ & $\checkmark$ & $\checkmark$ \\
\hline Year FE & $\checkmark$ & $\checkmark$ & $\checkmark$ & $\checkmark$ \\
\hline
\end{tabular}

This table reports difference-in-differences estimates of the effect of the foreign capital liberalization in the Prowess data set, taking into account cross-industry spillover effects. All dependent variables are in logs. Upstream J $_{j t}$ measures the composite reform shock from upstream industries, and Downstream $_{j t}$ measures the composite reform shock from downstream industries. Firms are observed between 1995 and 2015. Standard errors are twoway clustered at the 4-digit industry and year level. ${ }^{*},{ }^{* *}$, and $* * *$ denote $10 \%, 5 \%$, and $1 \%$ statistical significance respectively. 
Table A12: Heterogeneous Effects of Foreign Capital Liberalization, Accounting for Spillovers

\begin{tabular}{|c|c|c|c|c|}
\hline \multirow[t]{2}{*}{ Dependent Variable } & Revenues & Capital & Wages & MRPK \\
\hline & (1) & (2) & (3) & (4) \\
\hline Reform $_{j t} \times I_{i}^{\text {High MRPK }}$ & $\begin{array}{c}0.18^{* * *} \\
(0.05)\end{array}$ & $\begin{array}{c}0.60^{* * *} \\
(0.07)\end{array}$ & $\begin{array}{c}0.26^{* *} \\
(0.11)\end{array}$ & $\begin{array}{c}-0.44^{* * *} \\
(0.08)\end{array}$ \\
\hline Reform $_{j t}$ & $\begin{array}{c}0.11 \\
(0.08)\end{array}$ & $\begin{array}{l}-0.05 \\
(0.09)\end{array}$ & $\begin{array}{l}-0.02 \\
(0.08)\end{array}$ & $\begin{array}{c}0.06 \\
(0.13)\end{array}$ \\
\hline Upstream $_{j t}$ & $\begin{array}{l}-0.12 \\
(0.22)\end{array}$ & $\begin{array}{c}0.14 \\
(0.16)\end{array}$ & $\begin{array}{l}-0.00 \\
(0.16)\end{array}$ & $\begin{array}{c}-0.25^{*} \\
(0.13)\end{array}$ \\
\hline Downstream $_{j t}$ & $\begin{array}{c}0.33 \\
(0.29)\end{array}$ & $\begin{array}{c}0.09 \\
(0.19)\end{array}$ & $\begin{array}{c}0.25 \\
(0.30)\end{array}$ & $\begin{array}{c}0.26 \\
(0.17)\end{array}$ \\
\hline Observations & 51,541 & 51,244 & 37,598 & 49,026 \\
\hline Firm FE & $\checkmark$ & $\checkmark$ & $\checkmark$ & $\checkmark$ \\
\hline Year FE & $\checkmark$ & $\checkmark$ & $\checkmark$ & $\checkmark$ \\
\hline Age FE & $\checkmark$ & $\checkmark$ & $\checkmark$ & $\checkmark$ \\
\hline
\end{tabular}

This table reports estimates of the heterogeneous effects of foreign capital liberalization on capital constrained and unconstrained firms, controlling for spillovers through the input-output matrix. All dependent variables are in logs. Firms are observed between 1995 and 2015. Upstream Unt $_{j t}$ measures the composite reform shock from upstream industries, and Downstream ${ }_{j t}$ measures the composite reform shock from downstream industries. All regressions include firm fixed effects, survey year fixed effects, and firm age fixed effects. Firms are classified as constrained if their average MRPK in the pre-treatment period from 1995-2000 is above the 4-digit industry median. MRPK is calculated as $Y / K$. Standard errors are twoway clustered at the 4-digit industry and year level. *,**, and ${ }^{* * *}$ denote $10 \%, 5 \%$, and $1 \%$ statistical significance respectively. 
Table A13: Regression Estimates Used to Estimate the Effect of the Policy on the Manufacturing Solow Residual

\begin{tabular}{|c|c|c|c|c|c|c|}
\hline \multirow[t]{2}{*}{ Dependent Variable } & MRPK & MRPL & MRPM & Capital & Wages & Materials \\
\hline & (1) & (2) & (3) & (4) & $(5)$ & (6) \\
\hline Reform $_{j t}$ & $\begin{array}{l}0.30^{*} \\
(0.16)\end{array}$ & $\begin{array}{l}0.30^{*} \\
(0.17)\end{array}$ & $\begin{array}{c}0.18^{* * *} \\
(0.07)\end{array}$ & $\begin{array}{c}0.03 \\
(0.08)\end{array}$ & $\begin{array}{l}-0.12 \\
(0.11)\end{array}$ & $\begin{array}{l}-0.09 \\
(0.14)\end{array}$ \\
\hline Reform $_{j t} \times I_{i}^{\text {High MRPK }}$ & $\begin{array}{c}-0.56^{* * *} \\
(0.10)\end{array}$ & $\begin{array}{c}-0.21^{* * *} \\
(0.05)\end{array}$ & $\begin{array}{c}0.01 \\
(0.10)\end{array}$ & $\begin{array}{c}0.47^{* * *} \\
(0.14)\end{array}$ & $\begin{array}{c}0.31^{* * *} \\
(0.10)\end{array}$ & $\begin{array}{c}0.05 \\
(0.08)\end{array}$ \\
\hline $\operatorname{Reform}_{j t} \times I_{i}^{\text {High MRPL }}$ & $\begin{array}{l}-0.14^{*} \\
(0.08)\end{array}$ & $\begin{array}{c}-0.35^{* * *} \\
(0.10)\end{array}$ & $\begin{array}{c}-0.12^{* * *} \\
(0.04)\end{array}$ & $\begin{array}{l}0.22^{*} \\
(0.13)\end{array}$ & $\begin{array}{c}0.30^{* * *} \\
(0.12)\end{array}$ & $\begin{array}{l}0.22^{*} \\
(0.13)\end{array}$ \\
\hline Reform $_{j t} \times I_{i}^{\text {High MRPM }}$ & $\begin{array}{l}-0.07 \\
(0.10)\end{array}$ & $\begin{array}{l}-0.09 \\
(0.07)\end{array}$ & $\begin{array}{c}-0.23^{* * *} \\
(0.04)\end{array}$ & $\begin{array}{l}-0.10 \\
(0.10)\end{array}$ & $\begin{array}{l}-0.07 \\
(0.11)\end{array}$ & $\begin{array}{c}0.05 \\
(0.11)\end{array}$ \\
\hline Number of observations & 38,284 & 38,284 & 38,284 & 50,030 & 40,683 & 48,443 \\
\hline Firm FE & $\checkmark$ & $\checkmark$ & $\checkmark$ & $\checkmark$ & $\checkmark$ & $\checkmark$ \\
\hline Year FE & $\checkmark$ & $\checkmark$ & $\checkmark$ & $\checkmark$ & $\checkmark$ & $\checkmark$ \\
\hline
\end{tabular}

This table reports the difference-in-differences estimates used to estimate the policy's effects on the manufacturing Solow residual. All dependent variables are in logs. Firms are observed between 1995 and 2015. All regressions include firm fixed effects, survey year fixed effects, and firm age fixed effects. $I_{i}^{\text {High } M R P K}$ is coded as 1 if a firm's average MRPK in the pre-treatment period from 1995-2000 is above the 4-digit industry median, where MRPK is calculated us-

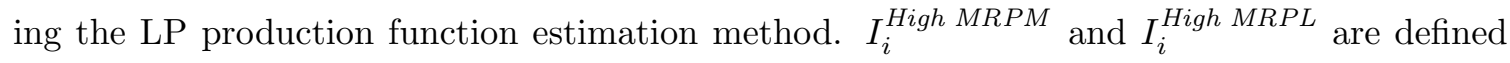
analogously for materials and labor. MRPK, MRPL, and MRPM are all estimated using production functions estimated with the methodology of Levinsohn and Petrin (2003). Standard errors are twoway clustered at the 4-digit industry and year level. *, **, and *** denote $10 \%$, $5 \%$, and $1 \%$ statistical significance respectively. 